HOUSING AND THE MACROECONOMY:

THE ROLE OF BAILOUT GUARANTEES FOR GOVERNMENT SPONSORED ENTERPRISES

\author{
Karsten Jeske \\ Dirk Krueger \\ Kurt Mitman \\ Working Paper 17537 \\ http://www.nber.org/papers/w17537 \\ NATIONAL BUREAU OF ECONOMIC RESEARCH \\ 1050 Massachusetts Avenue \\ Cambridge, MA 02138 \\ October 2011
}

We have benefited from helpful comments by seminar participants at the Wharton macro lunch, the Banco de Espana, The Housing Conference at the Bank of Canada and the Federal Reserve Bank of Atlanta. Krueger thanks the NSF for financial support under grants SES-0820494 and SES-1123547. The views expressed herein are those of the authors and do not necessarily reflect the views of Mellon Capital Management, The Bank of New York Mellon, or the National Bureau of Economic Research.

NBER working papers are circulated for discussion and comment purposes. They have not been peerreviewed or been subject to the review by the NBER Board of Directors that accompanies official NBER publications.

(C) 2011 by Karsten Jeske, Dirk Krueger, and Kurt Mitman. All rights reserved. Short sections of text, not to exceed two paragraphs, may be quoted without explicit permission provided that full credit, including $(\subset)$ notice, is given to the source. 
Housing and the Macroeconomy: The Role of Bailout Guarantees for Government Sponsored Enterprises

Karsten Jeske, Dirk Krueger, and Kurt Mitman

NBER Working Paper No. 17537

October 2011

JEL No. E21,G11,R21

\begin{abstract}
$\underline{\text { ABSTRACT }}$
This paper evaluates the macroeconomic and distributional effects of government bailout guarantees for Government Sponsored Enterprises (such as Fannie Mae and Freddy Mac) in the mortgage market. In order to do so we construct a model with heterogeneous, infinitely lived households and competitive housing and mortgage markets. Households have the option to default on their mortgages, with the consequence of having their homes foreclosed. We model the bailout guarantee as a government provided and tax-financed mortgage interest rate subsidy. We find that eliminating this subsidy leads to substantially lower equilibrium mortgage origination and increases aggregate welfare, but has little effect on foreclosure rates and housing investment. The interest rate subsidy is a regressive policy: eliminating it benefits low-income and low-asset households who did not own homes or had small mortgages, while lowering the welfare of high-income, high-asset households.
\end{abstract}

Karsten Jeske

Mellon Capital Management Corporation

Karstenj@mcm.com

Dirk Krueger

Department of Economics

University of Pennsylvania

3718 Locust Walk

Philadelphia, PA 19104

and NBER

dkrueger@econ.upenn.edu
Kurt Mitman

Department of Economics, McNeil 160

3718 Locust Walk

Philadelphia, PA 19104

mitmanke@econ.upenn.edu 


\title{
Housing and the Macroeconomy: The Role of Bailout Guarantees for Government Sponsored Enterprises*
}

\author{
Karsten Jeske \\ Mellon Capital Management Corporation \\ Dirk Krueger \\ Kurt Mitman \\ University of Pennsylvania, CEPR and NBER University of Pennsylvania
}

October 12, 2011

\begin{abstract}
This paper evaluates the macroeconomic and distributional effects of government bailout guarantees for Government Sponsored Enterprises (such as Fannie Mae and Freddy Mac) in the mortgage market. In order to do so we construct a model with heterogeneous, infinitely lived households and competitive housing and mortgage markets. Households have the option to default on their mortgages, with the consequence of having their homes foreclosed. We model the bailout guarantee as a government provided and tax-financed mortgage interest rate subsidy. We find that eliminating this subsidy leads to substantially lower equilibrium mortgage origination and increases aggregate welfare, but has little effect on foreclosure rates and housing investment. The interest rate subsidy is a regressive policy: eliminating it benefits low-income and low-asset households who did not own homes or had small mortgages, while lowering the welfare of high-income, high-asset households.

Keywords: Housing, Mortgage Market, Default Risk, Government-Sponsored Enterprises
\end{abstract}

JEL codes: E21, G11, R21

\section{Introduction}

The United States displays one of the highest home ownership rates in the world at close to 70\%, and owner-occupied houses constitute the most important asset for most U.S. households. Part of the attractiveness of owner-occupied housing stems from a variety of subsidies the government provides to homeowners. In addition to tax-deductible mortgage interest payments and the fact that implicit income from housing capital (i.e. the imputed rental-equivalent) is not taxable, a

*The second and third authors can be reached at dkrueger@econ.upenn.edu and mitmanke@econ.upenn.edu. We have benefited from helpful comments by seminar participants at the Wharton macro lunch, the Banco de Espana, The Housing Conference at the Bank of Canada and the Federal Reserve Bank of Atlanta. Krueger thanks the NSF for financial support under grants SES-0820494 and SES-1123547. 
third subsidy arises from government intervention in the mortgage market. In the US close to $50 \%$ of residential mortgages are held by so-called Government-Sponsored Enterprises (GSE's), totalling more that $\$ 5$ trillion. In September 2008, the US Treasury took conservatorship of Fannie Me and Freddie Mac after huge losses following the collapse of house prices. Since then, the US government has provided more than $\$ 153$ billion to help GSE's remain solvent. Policy makers are currently faced with deciding the future of GSE's and the role of the government in providing insurance in the mortgage market.

In this paper we ask what are the macroeconomic and distributional consequences of government guarantees for GSE's, such as Fannie Mae and Freddie Mac. We model the consequences of this bailout guarantee as a tax-financed mortgage interest rate subsidy. Prior to their bailout in 2008, the GSE's could borrow at interest rates close to that on U.S. government debt, despite the fact that they were heavily exposed to aggregate house price risk (as has become abundantly clear during the recent crisis). The absence of a significant risk premium can be attributed to the then implicit government bailout guarantee these institutions enjoyed. Currently the GSE's are explicitly backed by the US government and as a consequence enjoy lower borrowing costs than private companies. To the extend that part of the interest advantage of GSE's is passed through to homeowners (at least partially), there exists a mortgage interest rate subsidy from the federal government to homeowners. This subsidy must be financed by increased tax revenues, either to finance the bailout in case of a collapse in the housing market directly or to service the increased government debt resulting from the bailout.

In order to evaluate the aggregate and redistributive consequences of this subsidy we construct a heterogeneous agent general equilibrium model with incomplete markets in the tradition of Bewley (1986), Huggett (1993) and Aiyagari (1994). We augment this model by a real estate sector and we allow households to borrow against their real estate wealth positions through collateralized mortgages. In the model households can default on their mortgages, with the consequence of losing their homes. Competitive mortgage companies price the default risk into the mortgage interest rates they offer. The implicit (prior to 2008) or explicit (since 2008) support of GSE's is modeled as a tax-financed direct subsidy to mortgage interest rates. Our stationary economy corresponds to a world in which the government taxes income every period and either saves the proceeds in an effort to smooth out the spending shock triggered by a potential insolvency of the GSE's, or alternatively, is able to buy insurance against that shock from the outside world via, say, a market for credit derivatives. Under this interpretation the tax revenues constitute the required funds to cover the necessary insurance premium.

In addition to addressing the applied policy question stated above, we view as a second contribution of our paper the theoretical characterization of mortgage interest rates in our equilibrium model with foreclosure. First, we show that mortgages are priced exclusively based on leverage, with more highly levered households paying higher interest rates. This result is important because it provides a concise characterization of the mortgage price function which allows us to deal with the continuous choice of mortgage contracts by households. It also facilitates the efficient computation of an equilibrium in our model. Second, we prove that a minimum down payment requirement arises endogenously in our model. Finally, we provide a partial characterization of the household decision problem that provides insights into why households might simultaneously save in low interest bearing risk-free bonds and borrow in mortgages that carry higher interest rates. We therefore believe that our model provides a useful framework for future analyses of the housing and mortgage market with collateralized default, and consequently might be of 
independent interest.

Our quantitative results can be described as follows. First, comparing stationary equilibria with and without the policy, a tax-financed interest rate subsidy of 40 basis points ${ }^{1}$ leads to a significant increase in mortgage origination, but has little effect on investment in housing assets or in the equilibrium construction of real estate. The mortgage subsidy does not significantly change the share of households with positive holdings of real estate, because on one hand the subsidy makes real estate ownership more attractive, but on the other hand the higher required taxes lower net of tax income and thus discourage homeownership for low-income and low-asset households. However, the subsidy does significantly affect the distribution of leverage in the economy by increasing both the fraction of households that have positive mortgage debt and the level of leverage. This suggests that the GSE's may have led to over-investment in mortgages and excess household leverage, which may have exacerbated the response to the recent drop in house prices.

Using a steady state utilitarian social welfare functional we find that the aggregate welfare implications of the subsidy are negative, in the order of $0.8 \%$ of consumption equivalent variation. However, since households are heterogeneous, there is disagreement over the desirability of the subsidy. Low-wealth households prefer to live in a world without the subsidy, whereas highwealth households prefer to live in a world with the subsidy. This can be explained by the fact that low-wealth households hold little or no housing, and thus do not benefit from the subsidy, as compared to high wealth households that have large homes and mortgages.

\subsection{Related Literature}

Our paper aims at making two contributions, and thus is related to two broad strands of the literature. On the substantive side, it provides a quantitative, model-based analysis of the macroeconomic and distributional consequences of mortgage interest rate subsidies through guaranteeing the GSE's. It therefore complements empirical work that evaluates the importance of the GSE's and their government guarantee for the housing and mortgage market. Frame and Wall $(2002 a, b)$ and more recently Acharya et al. (2011) provide a thorough summary of the institutional details surrounding GSE's. We use the empirical estimates of CBO (2001) that quantified the borrowing interest rate advantage of GSE's to approximately 40 basis points to motivate our policy thought experiment. More broadly, our paper contributes to the literature that studies the positive and normative implications of government housing subsidies on equilibrium allocations. In this regard, our work is most closely related to Gervais (2001) who constructs a heterogeneous household general equilibrium life cycle model to evaluate the effects of the other two main government housing subsidies: the tax-deductibility of mortgage interest rates and the fact that the implicit income from owner-occupied housing capital is not subject to income taxation. Our contribution, relative to his, is to introduce mortgage default (foreclosure) into a dynamic general equilibrium model, and to use it to study a different government housing subsidy policy

Thus a second, model-building and theoretical contribution of the paper is to develop an equilibrium model with mortgage debt and foreclosure in which mortgage interest rates are

\footnotetext{
${ }^{1}$ The Congressional Budget Office (CBO, 2001) estimated that GSE's were able to borrow at a rate of roughly 40 basis points below that of private companies on account of the (at that time implicit) bailout guarantee. Several studies (e.g., Passmore, Sherlund and Burgess (2005) and Blinder, Flannery, and Kamihachi (2004)) have argued that a significant portion, if not all of the subsidy is passed on to homeowners.
} 
determined by competition of financial intermediaries, and fully reflect equilibrium default probabilities. In this regard, our model can be seen as a natural extension of the literature on uncollateralized debt and equilibrium default by Chatterjee et al. (2007) and Livshits et al. (2007). More broadly, our model shares many elements with the recent model-based quantitative housing literature. ${ }^{2}$ For example, Chambers et al. (2009) and Ríos- Rull and Sánchez-Marcos (2008) incorporate a housing tenure and mortgage choice into a general equilibrium framework. As we do, Gruber and Martin (2003) also study the distributional effects of the inclusion of housing wealth in a general equilibrium model, but do not address the role of government housing subsidies for this question.

Especially relevant for the purpose of our analysis are the three recent papers by Corbae and Quintin (2010), Chatterjee and Eyigungor (2011), and Garriga and Schlagenhauf (2009) that build general equilibrium models of housing that also feature equilibrium mortgage default, in order to evaluate the effects of the drop in house prices and a change in housing supply on equilibrium foreclosure rates. Their focus is mainly to understand the underlying reasons for and consequences of the recent foreclosure crisis $^{3}$ in the U.S. whereas our focus is on studying the effects of a specific government housing market policy. We see our paper as complementary to theirs in terms of focus, but also in terms of the details of how mortgages and foreclosure is modeled. In these papers mortgages are long term contracts whereas we permit households to costlessly refinance in every period. This modeling choice, in conjunction with perfect competition in the mortgage market allows us to obtain a sharp analytical characterization of equilibrium mortgage interest rates and default behavior in our model. ${ }^{4}$

The remainder of the paper is organized as follows. Section 2 introduces the model and defines equilibrium in an economy with a housing and mortgage market. Section 3 characterizes equilibria. Section 4 describes the calibration of our economy. Section 5 details the numerical results comparing two steady states in economies with and without a mortgage interest subsidy. Section 6 concludes the paper.

\section{The Model}

The economy is populated by a continuum of measure one of infinitely lived households, a continuum of competitive banks and a continuum of housing construction companies. As both the financial and the real estate sector is competitive and thus all firms will make zero profits in equilibrium we abstract from specifying ownership of the banks and real estate construction companies. Households face idiosyncratic endowment and house price shocks. In what follows we will immediately proceed to describing the economy recursively.

\footnotetext{
${ }^{2}$ For a brief survey, see Fernandez-Villaverde and Krueger (2011).

${ }^{3}$ An important, empirically oriented literature, has recently studied the causes and consequences of the recent boom in foreclosures in the U.S. See e.g. Campbell et al. (2011), Gerardi et al. (2009) or Mian et al. (2011).

${ }^{4}$ Krainer et al. (2009) construct a dynamic stochastic continuous time mortgage valuation model and also provide a partial analytical characterization of the interest rate and asset value of mortgages, as a function of the mortgage leverage.
} 


\subsection{Households}

Preferences: Households derive period utility $U(c, h)$ from consumption and housing services $h$, which can be purchased at a price $p_{l}$ (relative to the numeraire consumption good). Households discount the future with discount factor $\beta$ and are expected utility maximizers.

Endowments: Households receive an idiosyncratic endowment of the perishable consumption good given by $y \in Y$. These endowments follow a finite state Markov chain with transition probabilities $\pi\left(y^{\prime} \mid y\right)$ and unique invariant distribution $\Pi(y)$. We denote by $\bar{y}=\sum_{y \in Y} y \Pi(y)$ the average endowment. We will use the terms endowment and (labor) income interchangeably throughout the remainder of the paper, and assume that a law of large number applies, so that $\pi$ and $\Pi$ also denote deterministic fractions of households receiving a particular income shock $y$.

The government levies a proportional tax $\tau$ on labor income to finance an interest rate subsidy, if such a policy is in place.

Assets: In addition to consumption and housing services the household spends income to purchase two types of assets, one-period pure discount bonds $b^{\prime}$ and perfectly divisible houses $g^{\prime}$. The price of bonds is denoted by $P_{b}$ and the price of houses by $P_{h}$. Houses are risky assets: they are subject to idiosyncratic house price shocks. Let $F\left(\delta^{\prime}\right)$ denote the continuously differentiable cumulative distribution function of the price depreciation rate $\delta^{\prime}$ tomorrow, which has support $D=[\underline{\delta}, 1]$ with $\underline{\delta} \leq 0$. A negative value of $\delta$ indicates positive house price appreciation. We assume that the realization of $\delta$ is independent across time for every household, and that a law of large number applies, so that $F($.$) is also the economy-wide distribution of house price shocks.$

One unit of the housing asset generates one unit of housing services. A house purchased in the current period can immediately be rented out and thus generates rental income in the same period as the purchase. Households are prohibited from selling bonds and houses short.

Mortgages: Households can borrow against their real estate property. Let $m^{\prime}$ denote the size of the mortgage, and $P_{m}$ the contemporaneous receipts of resources (that is, of the consumption good) for each unit of mortgage issued today and to be repaid in the subsequent period. The "price" $P_{m}$ will be determined in equilibrium by competition of banks through a zero profit condition, and will in general depend on the characteristics of households as well as the size of the mortgage $m^{\prime}$ and size of the collateral $g^{\prime}$ against which the mortgage is issued. The gross mortgage interest rate is simply given by $R_{m}=1 / P_{m}$.

Households that come into the next period with housing assets $g^{\prime}$ and a mortgage $m^{\prime}$ possess the option, after having observed the idiosyncratic house price appreciation shock $\delta^{\prime}$, of defaulting on their mortgages, at the cost of losing their entire housing collateral. There are no other costs associated with defaulting on the mortgage and having one's housing asset foreclosed. This assumption, together with modeling mortgages as short-term contracts, immediately implies that households will choose to default whenever the amount owed on the mortgage is greater than the value of the house after the realization of the price shock, that is, if and only if ${ }^{5}$

$$
m^{\prime}>P_{h}\left(1-\delta^{\prime}\right) g^{\prime} .
$$

\footnotetext{
${ }^{5}$ We make the tie-breaking assumption that a household indifferent between defaulting and not defaulting will choose not to do so.
} 
As a consequence, the ex-ante default probability of a household at mortgage origination, that is, prior to observing the shock, is simply a function of the size of the mortgage $m^{\prime}$ and today's value of the collateral $g^{\prime} P_{h}$. As argued below, this will imply that in equilibrium the price of a mortgage $P_{m}$ today will only be a function of $\left(m^{\prime}, g^{\prime}\right)$, a fact we will use when now specifying the household problem in recursive formulation.

Recursive Formulation of the Household Problem: Let $a$ denote cash at hand, that is, after tax endowment plus the value from all assets brought into the period, after the current income and house price shocks $(y, \delta)$ have materialized. The individual state of a household consists of $s=(a, y)$. The cross-sectional distribution over individual states is denoted by $\mu$. Since we will restrict our analysis to stationary equilibria in which $\mu$ is constant over time, in what follows the dependence of aggregate prices and quantities on $\mu$ is left implicit.

The dynamic programming problem of a household consists of choosing consumption $c$, housing services $h$ and a portfolio of financial and housing assets $\left(b^{\prime}, g^{\prime}\right)$ as well as mortgage positions $m^{\prime}$ to solve:

$$
v(s)=\max _{c, h, b^{\prime}, m^{\prime}, g^{\prime} \geq 0}\left\{U(c, h)+\beta \sum_{y^{\prime}} \pi\left(y^{\prime} \mid y\right) \int_{\underline{\delta}}^{1} v\left(s^{\prime}\right) d F\left(\delta^{\prime}\right)\right\}
$$

subject to

$$
\begin{gathered}
c+b^{\prime} P_{b}+h P_{l}+g^{\prime} P_{h}-m^{\prime} P_{m}\left(g^{\prime}, m^{\prime}\right)=a+g^{\prime} P_{l} \\
\left.a^{\prime}\left(\delta^{\prime}, y^{\prime}, m^{\prime}, g^{\prime}\right)=b^{\prime}+\max \left\{0, P_{h}\left(1-\delta^{\prime}\right) g^{\prime}-m^{\prime}\right)\right\}+(1-\tau) y^{\prime}
\end{gathered}
$$

Note that because of the assumption that newly purchased housing assets can immediately be rented out, rental income $g^{\prime} P_{l}$ from newly purchased housing assets enters the current period budget constraint. Tomorrow's cash at hand $a^{\prime}$ is equal to the sum of after tax labor income $(1-\tau) y^{\prime}$, the amount of bonds $b^{\prime}$ brought into the period and the net value of real estate. If the household owes less than the realized value of her housing asset, she does not default and the net value of real estate equals $P_{h}\left(1-\delta^{\prime}\right) g^{\prime}-m^{\prime}$. Alternatively, for unfavorable realization of the house price shock $\delta^{\prime}$ the mortgage is under water, the household defaults and is left with zero housing wealth.

\subsection{The Real Estate Construction Sector}

The representative firms in the perfectly competitive real estate construction sector face the linear technology

$$
I=C_{h}
$$

where $I$ is the output of newly build and perfectly divisible houses of a representative firm and $C_{h}$ is the input of the consumption good. Note that we assume that this technology is reversible, that is, real estate companies can turn houses back into consumption goods using the same technology (although this does not happen in the equilibrium of our calibrated economies). Thus the problem of a representative firm reads as

$$
\begin{aligned}
& \max _{I, C_{h}} P_{h} I-C_{h} \\
& \text { s.t. } \\
& I= C_{h}
\end{aligned}
$$


and the equilibrium house price necessarily satisfies

$$
P_{h}=1
$$

In effect, ours is a model with exogenous house prices normalized to $P_{h}=1$, but endogenous rents and thus endogenous house-price to rent ratios), and perfectly elastic supply of the housing asset from the real estate companies at that exogenous house price.

\subsection{The Banking Sector}

Let $r_{b}$ denote the risk free interest rate on one-period bonds, to be determined in general equilibrium. Competitive banks take their costs $P_{b}=\frac{1}{1+r_{b}}$ of re-financing as given. In addition, we assume that issuing mortgages is costly; let $r_{w}$ be the percentage real resource cost, per unit of mortgage issued, to the bank. This cost captures screening costs, administrative costs as well as maintenance costs of the mortgage (such as preparing and mailing a quarterly mortgage balance). In addition, in order to insure mortgages against the (unmodeled) aggregate component of mortgage default risk, banks need to purchase insurance at a cost $\theta$ for each dollar of mortgage originated. We think of this $\theta$ as a real resource cost that is transferred to an unmodeled insurance company abroad.

The government can subsidize mortgages using receipts from labor income taxes. We model any mortgage subsidy as an interest rate subsidy $\phi$ for each unit of mortgage originated. Thus, as a consequence, the effective net cost of the banking sector for financing one dollar of mortgage equals $r_{b}+r_{w}+\theta-\phi$. We will consider two polar cases: one in which the government subsidizes the mortgage exactly at the rate equal to the cost of insurance against aggregate risk, $\phi=\theta$ (which we think of as the bailout policy being in place), and one in which the government and thus the bailout policy is absent, $\phi=0$.

In the perfectly competitive banking sector, risk-neutral banks compete for customers loan by loan, as in Chatterjee et al. (2007), in the context of uncollateralized debt. Banks will only originate mortgages that yield non-negative profits in expectation. Banks, when making their origination decision, take into account the fact that a household may default on its mortgage. When a household does so, the bank seizes the housing collateral worth $\left(1-\delta^{\prime}\right) g^{\prime}$. However, we assume that the technology for foreclosing is possibly inefficient, and therefore that the bank only recovers a fraction $\gamma \leq 1$ of the value of the collateral.

For ease of exposition we assume that the cost $r_{w}$ of mortgage generation is paid when the mortgage is repaid, and not when it is issued. This implies that households defaulting on their mortgage payments also default on paying for the cost of generating the mortgage. Note that since this cost is fully priced into the mortgage and thus reflected in $P_{m}$, this assumption is without loss of generality but makes the notation in the banks' problem less cumbersome.

In order to define a typical banks' problem we first have to characterize the optimal default choice of a household. As argued in section 2.1 the household defaults if and only if her mortgage is under water. Thus for a household with housing assets $g^{\prime}$ and a mortgage $m^{\prime}$ there is a cutoff level for house price depreciation $\delta^{*}\left(m^{\prime}, g^{\prime}\right)$ at which a household is indifferent between defaulting and not defaulting on her mortgage. It is determined as

$$
m^{\prime}=\left(1-\delta^{*}\left(m^{\prime}, g^{\prime}\right)\right) g^{\prime}
$$


and thus explicitly

$$
\delta^{*}\left(m^{\prime}, g^{\prime}\right)=\delta^{*}\left(\kappa^{\prime}\right)=1-\frac{m^{\prime}}{g^{\prime}}=1-\kappa^{\prime}
$$

where $\kappa^{\prime}=\frac{m^{\prime}}{g^{\prime}}$ is defined as the leverage (for $g^{\prime}>0$ ) of a mortgage $m^{\prime}$ backed by real estate $g^{\prime}$. Thus the household defaults for all house price depreciation realizations $\delta^{\prime}>\delta^{*}\left(\kappa^{\prime}\right)$. Whenever $\delta^{*}\left(\kappa^{\prime}\right)<\underline{\delta}$ (e.g. if $g^{\prime}=0$ and thus $\kappa^{\prime}=\infty$ ) the household defaults for sure in the next period and we set $\delta^{*}\left(\kappa^{\prime}\right)=\underline{\delta}$, that is, formally

$$
\delta^{*}\left(\kappa^{\prime}\right)=\max \left\{\underline{\delta}, 1-\kappa^{\prime}\right\}
$$

Note again that since the foreclosure decision of a household does not depend on the bond holdings $b^{\prime}$ chosen today or current income $y$ of the household, in equilibrium the receipts $P_{m}$ will not depend on those quantities either.

Using the characterization of the household default decision, we can characterize the set of mortgage contracts that the bank will originate. A bank will originate a mortgage if and only if:

$$
m^{\prime} P_{m}\left(g^{\prime}, m^{\prime}\right) \leq \frac{1}{1+r_{b}+r_{w}+\theta-\phi}\left\{m^{\prime} F\left(\delta^{*}\left(\kappa^{\prime}\right)\right)+\gamma g^{\prime} \int_{\delta^{*}\left(\kappa^{\prime}\right)}^{1}\left(1-\delta^{\prime}\right) d F\left(\delta^{\prime}\right)\right\}
$$

The left hand side $m^{\prime} P_{m}\left(g^{\prime}, m^{\prime}\right)$ is the amount the bank pays out to a household that takes on a mortgage of size $m^{\prime}$ collateralized by $g^{\prime}$ housing assets. The term in \{\} -brackets are the receipts tomorrow for the bank from the mortgage. With probability $F\left(\delta^{*}\left(\kappa^{\prime}\right)\right)$ the household receives a house price shock $\delta^{\prime}$ that makes default suboptimal in which case she repays the full face value of the mortgage $m^{\prime}$. For all price shocks $\delta^{\prime}>\delta^{*}\left(\kappa^{\prime}\right)$ the household defaults and the bank retrieves $\gamma\left(1-\delta^{\prime}\right) g^{\prime}$ by foreclosing and selling off the house. For each dollar of mortgage issued today the costs of funds to the bank are $1+r_{b}$, the direct costs of maintaining one dollar worth of mortgage are $r_{w}$, the insurance costs per dollar of mortgage are $\theta$ and the subsidy per dollar is $\phi$, so that the effective discount factor of the bank is given by $\frac{1}{1+r_{b}+r_{w}+\theta-\phi}$.

Notice that one direct and obvious consequence of equation (6) is that $P_{m}\left(g^{\prime}=0, m^{\prime}\right)=0$ for all $m^{\prime}>0$, that is, a mortgage $m^{\prime}>0$ without collateral, i.e. with $g^{\prime}=0$, will not generate any funds for the household today. Without collateral $\left(g^{\prime}=0\right)$ and $m^{\prime}>0$ the household will default on the mortgage for sure tomorrow and foreclosure will not generate any revenues for the bank. Therefore the right-hand size of equation (6) equals zero, and thus $P_{m}\left(g^{\prime}=0, m^{\prime}\right)=0$

\subsection{The Government}

As stated above, the government levies income taxes at a flat rate $\tau$ on households to finance the mortgage interest rate subsidy. The tax revenues of the government are given by $\tau \bar{y}$. In the baseline economy, as discussed above, we model the bailout guarantee provided by the government as an interest rate subsidy equal to the cost of insurance $\phi=\theta$. We interpret this as the government levying income taxes to provide insurance to banks against systemic mortgage risk. The overall costs of the interest rate subsidy can be calculated as follows. For a loan of given size $m^{\prime}$ the resources advanced to the household today by the bank are $m^{\prime} P_{m}\left(g^{\prime}, m^{\prime} ; \phi=\theta\right)$. If there were no subsidy, these would be $m^{\prime} P_{m}\left(g^{\prime}, m^{\prime} ; \phi=0\right)$. 
Thus the subsidy to a mortgage taker by the government is ${ }^{6}$ :

$$
\operatorname{sub}\left(m^{\prime}, g^{\prime}\right)=m^{\prime}\left[P_{m}\left(g^{\prime}, m^{\prime} ; \phi=\theta\right)-P_{m}\left(g^{\prime}, m^{\prime} ; \phi=0\right)\right]
$$

and the total economy-wide subsidy is ${ }^{7}$

$$
\Phi=\int \operatorname{sub}\left(m^{\prime}, g^{\prime}\right) d \mu
$$

Note that $\Phi$ also measures the amount of resources expended on insurance against aggregate shocks, either by the households directly (in case of no bailout policy) or by the government. The income tax rate then has to satisfy

$$
\tau=\frac{\Phi}{\bar{y}}
$$

To summarize, the two policies we will compare are

Case 1 [Benchmark] Government Bailout/Subsidy: Households face mortgage prices $P_{m}\left(g^{\prime}, m^{\prime} ; \phi=\right.$ $\theta$ ) and taxes $\tau$ given by (7)

Case 2 [Counterfactual] No Government Bailout/Subsidy: Households face mortgage prices $P_{m}\left(g^{\prime}, m^{\prime} ; \phi=0\right)$ and taxes $\tau=0$.

\subsection{Equilibrium}

We are now ready to define a stationary recursive Competitive Equilibrium for the benchmark economy. Let $S=\mathbb{R}_{+} \times Y$ denote the individual state space.

Definition Given a government subsidy policy $\phi$ a Stationary Recursive Competitive Equilibrium are value and policy functions for the households, $v, c, h, b^{\prime}, m^{\prime}, g^{\prime}: S \rightarrow \mathbb{R}$, policies for the real estate construction sector $I, C_{h}$, prices $P_{l}, P_{b}$, mortgage pricing function $P_{m}: \mathbb{R}_{+} \times \mathbb{R}_{+} \rightarrow \mathbb{R}$, a government tax rate $\tau$ and a stationary measure $\mu$ such that

1. (Household Maximization) Given prices $P_{l}, P_{b}, P_{m}$ and government policies the value function solves (1) and $c, h, b^{\prime}, m^{\prime}, g^{\prime}$ are the associated policy functions.

2. (Real Estate Construction Company Maximization) Policies $I, C_{h}$ solve (4).

3. (Loan-by-Loan Competition) Given $P_{b}$ and $P_{m},(6)$ holds with equality for all $m^{\prime}, g^{\prime}$.

\footnotetext{
${ }^{6}$ Here $P_{m}\left(g^{\prime}, m^{\prime} ; \phi=\theta\right)$ and $P_{m}\left(g^{\prime}, m^{\prime} ; \phi=0\right)$ denote the mortgage pricing functions for the same interest rate $r_{b}$, that is, $P_{m}\left(g^{\prime}, m^{\prime} ; \phi=0\right)$ is the hypothetical mortgage pricing function without the subsidy, but evaluated at the interest rate $r_{b}$ in the economy with the subsidy.

${ }^{7}$ Note that in equilibrium when all loans make exactly zero profits,

$$
\operatorname{sub}\left(m^{\prime}, g^{\prime}\right)=\frac{\theta m^{\prime} P_{m}\left(g^{\prime}, m^{\prime} ; \phi=\theta\right)}{1+r_{b}+r_{w}+\theta} .
$$

That is, the cost of the subsidy per dollar of mortgage generated for the government is $\frac{\theta}{1+r_{b}+r_{w}+\theta} \approx \theta$.
} 
4. (Government Budget Balance) The tax rate function $\tau$ satisfies (7), given the functions $m^{\prime}, P_{m}$.

5. (Market Clearing in Rental Market)

$$
\int g^{\prime}(s) d \mu=\int h(s) d \mu
$$

6. (Market Clearing in the Bond Market)

$$
\int P_{b} b^{\prime}(s) d \mu=\int P_{m}\left(g^{\prime}(s), m^{\prime}(s)\right) m^{\prime}(s) d \mu
$$

7. (Market Clearing in the Goods Market)

$$
\int c(s) d \mu+I+\Phi=\bar{y}
$$

8. (Invariance of Distribution $\mu$ ). The measure $\mu$ is invariant with respect to the Markov process induced by the exogenous Markov process $\pi$ and the policy functions $m^{\prime}, g^{\prime}, b^{\prime}$.

When we derive the welfare consequences of removing the mortgage interest subsidy, we measure aggregate economy-wide welfare via a Utilitarian social welfare function in the steady state, defined as

$$
\mathcal{W E} \mathcal{L}=\int v(s) \mu(d s)
$$

where $\mu$ is the invariant measure over the state space for cash at hand and income, $s=(a, y)$.

\section{Theoretical Results}

In this section we state theoretical properties of our model that provide insights into the forces that determine optimal household portfolio and leverage choices, but are also useful in the computation of the equilibria. We fully characterize mortgage interest rates and prove the existence of an endogenous down payment requirement. Next, we prove the existence of a solution to the household problem and provide a partial characterization of the household portfolio choice. Finally, we derive an upper bound on the equilibrium rental price $P_{l}$.

\subsection{Mortgage Interest Rates}

Define the implied net real interest rate from a mortgage $m^{\prime}$ with collateral $g^{\prime}$ receipts $P_{m}\left(g^{\prime}, m^{\prime}\right)$ as:

$$
r_{m}\left(g^{\prime}, m^{\prime}\right)=\frac{1}{P_{m}\left(g^{\prime}, m^{\prime}\right)}-1
$$

From equation (6) and the fact that competition requires profits for all mortgages issued in equilibrium to be zero we immediately obtain a characterization of equilibrium mortgage interest rates: 
Proposition 1 In any steady-state equilibrium, mortgages originated with positive collateral $g^{\prime}>$ 0 have the following properties:

1. They are priced exclusively based on leverage $\kappa^{\prime}=\frac{m^{\prime}}{g^{\prime}}$, that is $P_{m}\left(m^{\prime}, g^{\prime}\right)=P_{m}\left(\kappa^{\prime}\right)$ and $r_{m}\left(\kappa^{\prime}\right)$.

2. $P_{m}\left(\kappa^{\prime}\right)$ is decreasing in $\kappa^{\prime}$, and strictly decreasing if the household defaults with positive probability. Thus mortgage interest rates $r_{m}\left(\kappa^{\prime}\right)$ are increasing in leverage $\kappa^{\prime}$.

3. Households that repay their mortgage with probability one have $\delta^{*}\left(\kappa^{\prime}\right)=1$ and thus $P_{m}\left(\kappa^{\prime}\right)=$ $\left(\frac{1}{1+r_{b}+r_{w}+\theta-\phi}\right)$, i.e. they can borrow at the rate $r_{b}+r_{w}+\theta-\phi$.

4. Households that default with positive probability tomorrow receive $P_{m}\left(\kappa^{\prime}\right)<\left(\frac{1}{1+r_{b}+r_{w}+\theta-\phi}\right)$ today, that is, they borrow with a risk premium $r_{m}\left(\kappa^{\prime}\right)>r_{b}+r_{w}+\theta-\phi$.

Proof. In equilibrium equation (6) becomes (by dividing both sides by mortgage size $m^{\prime}>0$ ):

$$
\begin{aligned}
P_{m}\left(g^{\prime}, m^{\prime}\right) & =\frac{1}{m^{\prime}}\left[\left(\frac{1}{1+r_{b}+r_{w}+\theta-\phi}\right)\left\{m^{\prime} F\left(\delta^{*}\left(m^{\prime}, g^{\prime}\right)\right)+\gamma g^{\prime} \int_{\delta^{*}\left(m^{\prime}, g^{\prime}\right)}^{\infty}\left(1-\delta^{\prime}\right) d F\left(\delta^{\prime}\right)\right\}\right] \\
& =\left(\frac{1}{1+r_{b}+r_{w}+\theta-\phi}\right)\left\{F\left(\delta^{*}\left(\kappa^{\prime}\right)\right)+\frac{\gamma}{\kappa^{\prime}} \int_{\delta^{*}\left(\kappa^{\prime}\right)}^{\infty}\left(1-\delta^{\prime}\right) d F\left(\delta^{\prime}\right)\right\} \\
& =P_{m}\left(\kappa^{\prime}\right)
\end{aligned}
$$

which proves the mortgages are priced exclusively on leverage. The second and third points follow from the definition of the CDF of $\delta^{\prime}$ and the optimal default choice $\delta^{*}\left(\kappa^{\prime}\right)$. To prove the final point, note that for all $\delta^{\prime}>\delta^{*}\left(\kappa^{\prime}\right)$ we have $\frac{\gamma}{\kappa^{\prime}}\left(1-\delta^{\prime}\right)<1$.

This characterization of equilibrium mortgage interest rates now allows us to obtain an endogenous upper bound for the leverage.

\subsection{Endogenous Down Payment Requirement}

It is straightforward to show that it is never strictly beneficial for a household to purchase a mortgage with a leverage higher than the level that leads to subsequent default with probability one. Define the leverage that leads to certain default by $\bar{\kappa}$. At this amount of leverage, even the most favorable realization of the house price shock leads to default, that is $\delta^{*}(\bar{\kappa})=\underline{\delta}$. From equation (5) it follows that

$$
\bar{\kappa}=1-\underline{\delta}
$$

We now show that there exists a tighter endogenous upper bound on leverage $\kappa^{*}<\bar{\kappa}$ that households will never choose to exceed in equilibrium. This result also implies that it is never optimal for the household to lever up to the point in which default occurs with probability 1. Furthermore we demonstrate that, at least with $\underline{\delta}=0$, any mortgage chosen by households in equilibrium requires a positive down payment. 
Proposition 2 If $F(\delta)$ is $\mathcal{C}^{2}$ and log-concave with support $[\underline{\delta}, 1], \underline{\delta} \leq 0$, there exists an endogenous borrowing limit $\kappa^{*}$. That is, it is never optimal for a household to choose leverage $\kappa>\kappa^{*}$ at equilibrium mortgage prices $P_{m}$. Further, $\kappa^{*}<\bar{\kappa}$. In addition, if $\underline{\delta}=0$, then $\kappa^{*}<1$, that is, there is an endogenous minimum down payment $1-\kappa^{*}>0$.

Proof. See Appendix

Log-concavity of the distribution guarantees that the resources received today $m^{\prime} P_{m}\left(\kappa^{\prime}\right)$ will be concave in $m^{\prime}$. This fact, combined with the smoothness assumption on the distribution of the house price shocks, guarantees that the leverage that maximizes resources today will be strictly less than the leverage that leads which to certain default. By increasing leverage beyond the level that maximizes resources today, the household receives strictly less resources today and has to repay weakly more resources tomorrow, implying that it can never be optimal for the household to take on leverage above the level that maximizes contemporaneous resources received from the mortgage.

Note that the (truncated) Pareto distribution which we will use in our quantitative analysis for $F(\delta)$ is $\mathcal{C}^{2}$ and log-concave.

\subsection{Characterization of the Household Problem}

We now show that the recursive problem of the household has a unique solution and provide a partial characterization of the optimal decision rules. In order to do so it is helpful to split the household problem into a static problem that optimally allocates a given amount of resources between consumption and rental expenditures, and a dynamic consumption-saving and portfolio choice problem. ${ }^{8}$

As a function of the rental price $P_{l}$ and total expenditures $c$, define the indirect static utility function $u$ as the solution to:

$$
\begin{aligned}
u\left(c ; P_{l}\right)= & \max _{\tilde{c}, h \geq 0} U(\tilde{c}, h) \\
& \text { s.t. } \\
\tilde{c}+P_{l} h= & c
\end{aligned}
$$

Note that, in slight abuse of notation, $c$ now denotes total expenditures $\tilde{c}+P_{l} h$ as opposed to just nondurable consumption (as it was defined in previous sections).

The dynamic household maximization problem can then be rewritten as:

$$
\begin{aligned}
v(s)=\max _{c, b^{\prime}, m^{\prime}, g^{\prime} \geq 0}\left\{u\left(c ; P_{l}\right)+\beta \sum_{y^{\prime}} \pi\left(y^{\prime} \mid y\right) \int_{\underline{\delta}}^{\infty} v\left(s^{\prime}\right) d F\left(\delta^{\prime}\right)\right\} \\
\text { s.t. } \quad c+b^{\prime} P_{b}+g^{\prime}\left[1-P_{l}\right]-m^{\prime} P_{m}\left(\kappa^{\prime}\right)=a \\
\left.a^{\prime}\left(\delta^{\prime}, h^{\prime}, m^{\prime}, g^{\prime}\right)=b^{\prime}+\max \left\{0,\left(1-\delta^{\prime}\right) g^{\prime}-m^{\prime}\right)\right\}+(1-\tau) y^{\prime}
\end{aligned}
$$

In the appendix we prove that the recursive problem of the household has a unique solution:

\footnotetext{
${ }^{8}$ Clearly our ability to do so hinges crucially on the existence of frictionless housing and rental markets and the perfect substitutability of owner occupied housing and rentals in providing housing service flows.
} 
Proposition 3 Suppose that $u\left(. ; P_{l}\right)$ is unbounded from below and bounded from above. Then recursive problem of the household has a unique solution $v(a, y)$ that is strictly increasing in its first argument $a$.

Proof. See appendix

The fact that the utility function is bounded from above guarantees that even as the cash at hand of a household diverges, the value function will remain bounded. Therefore, since the utility function is unbounded from below, it will always be optimal to set consumption expenditures $c$ strictly away from zero, since contemporaneous utility diverges to negative infinity as consumption goes to zero, but the continuation value is bounded for all levels of saving. Note that if the utility function $U$ will be of CRRA form with risk aversion coefficient $\sigma>1$ (and a Cobb-Douglas aggregator between consumption and housing services) as we will assume in our quantitative analysis, then the indirect utility function $u$ satisfies the assumptions made in proposition 3.

We now give a partial characterization of the household decision problem. For doing so it is useful to define as

$$
P\left(\kappa^{\prime}\right):=1-P_{l}-\kappa^{\prime} P_{m}\left(\kappa^{\prime}\right)
$$

the net, per unit resources required to purchase $g^{\prime}$ housing assets, partially financed by a mortgage with leverage $\kappa^{\prime}=m^{\prime} / g^{\prime}$. Note that

$$
g^{\prime} P\left(\kappa^{\prime}\right)=\left(1-P_{l}\right) g^{\prime}-m^{\prime} P_{m}\left(m^{\prime} / g^{\prime}\right)
$$

Using this definition we can state the following:

Proposition 4 If $u\left(c ; P_{l}\right)$ is differentiable in $c$, then for any state $s$ for which it is optimal to choose an interior solution to the portfolio choice problem $\left(g^{\prime}, b^{\prime}, m^{\prime}>0\right)$, the Euler equation governing for the household is given by:

$$
\left[P_{b}+P^{\prime}\left(\kappa^{\prime}\right)\right]=\left[1-F\left(1-\kappa^{\prime}\right)\right] \beta \sum_{y^{\prime} \in Y} \pi\left(y^{\prime} \mid y\right)\left[\frac{u^{\prime}\left(c\left(b^{\prime}+(1-\tau) y^{\prime}, y^{\prime}\right) ; P_{l}\right)}{u^{\prime}\left(c(a, y) ; P_{l}\right)}\right]
$$

Further, at any such point the optimal leverage chosen by the household is determined by the equation:

$$
P\left(\kappa^{\prime}\right)-\left(1+\kappa^{\prime}\right) P^{\prime}\left(\kappa^{\prime}\right)=1-P_{l}
$$

Proof. The result is a direct consequence of Theorem 3 in Clausen and Strub (2011). The technical details are given in the appendix, section 7.2.3.

This partial characterization helps illustrate why households might simultaneously choose to borrow and save. First, note from Proposition 1 that when the default probability is zero, in the benchmark case with subsidy, households can borrow at a rate $r_{b}+r_{w}$ and save in bonds at rate $r_{b}$. If $r_{w}$ were to equal zero, there would be an indeterminacy between saving and borrowing, conditional on choosing mortgages with zero default probability. Having a positive cost of issuing a mortgage, $r_{w}>0$, eliminates that indeterminacy and creates a wedge between the borrowing and saving rate, even in the absence of default. However, even when there is a wedge in the interest rates between borrowing and saving, it may be optimal for households to simultaneously 
save and hold mortgages (i.e. borrow). To understand why, first consider the left-hand side of equation (8). It represents the resources that need to be paid today by to marginally increase leverage and use the funds from the additional mortgages $m^{\prime}$ to purchase more bonds $b^{\prime}$. We interpret this as the insurance premium of borrowing to save at the risk free rate. The right-hand side represents the expected stochastic discount factor, but only for states in which the household defaults in the next period. Only the default states are relevant for this trade-off: in states for which the household does not default the marginal increase in bond positions is exactly offset by the marginal increase in mortgage debt, leaving the net wealth position unchanged. When the household does default, however, she keeps the bonds without having to repay the mortgage. The risk-free bonds thus provide insurance against low consumption in default states. The trade-off reflected in (8) then is between the cost of "insurance" today, given today's consumption, and the marginal increase in consumption tomorrow from the payoff of the additional risk-free bonds $b^{\prime}$.

Equation (9) shows that conditional on wanting to "borrow to save" there is a unique optimal value $\kappa^{\prime}$ at which to do so. Thus the proposition predicts that the optimal policy function for leverage is flat over the region of the state space for which the household finds it optimal to borrow, in order to save. Our quantitative analysis below will demonstrate that households find it indeed optimal to do so for a significant part of the state space.

\subsection{Bounds on the Equilibrium Rental Price of Housing}

After having partially characterized the household problem we now derive an upper bound on the rental price, one of the two prices to be determined in general equilibrium. In addition, we pro Above we provided a full characterization of the mortgage pricing function $P_{m}$, and the remaining equilibrium price $P_{b}$, as in any Bewley type model with infinitely lived consumers, satisfies $P_{b}<1 / \beta$.

\subsubsection{An Upper Bound}

For all feasible choices of the household it has to be the case that $P\left(\kappa^{\prime}\right)=1-P_{l}-\kappa^{\prime} P_{m}\left(\kappa^{\prime}\right) \geq 0$,

otherwise the household can obtain a positive cash flow today by buying a house with a mortgage; the default option on the mortgage guarantees that the cash flow from the house tomorrow is non-negative. Thus, the requirement of absence of this arbitrage opportunity in equilibrium requires $P\left(\kappa^{\prime}\right) \geq 0$ for all $\kappa^{\prime}$, and, in particular, for $\kappa^{\prime}=\bar{\kappa}$. Thus

$$
P\left(\kappa^{\prime}=\bar{\kappa}\right)=1-P_{l}-\bar{\kappa} P_{m}\left(\kappa^{\prime}=\bar{\kappa}\right) \geq 0
$$

which implies

$$
\begin{aligned}
P(\bar{\kappa}) & =1-P_{l}-\bar{\kappa} P_{m}(\bar{\kappa}) \\
& =1-P_{l}-\left(\frac{1}{1+r_{b}+r_{w}}\right) \gamma\left(1-E\left(\delta^{\prime}\right)\right) \geq 0 \\
P_{l} & \leq 1-\left(\frac{1}{1+r_{b}+r_{w}}\right) \gamma\left(1-E\left(\delta^{\prime}\right)\right) \\
& =\frac{r_{b}+r_{w}+\gamma E\left(\delta^{\prime}\right)+1-\gamma}{1+r_{b}+r_{w}}
\end{aligned}
$$


which places an upper bound on the equilibrium rental price. If $\gamma=1$, this condition simply states that the rental price $P_{l}$ cannot be larger than the user cost of housing, inclusive of the $\operatorname{cost} r_{w}$ of originating mortgages $\frac{r_{b}+r_{w}+E\left(\delta^{\prime}\right)}{1+r_{b}+r_{w}}$.

\subsubsection{Towards A Lower Bound}

Due to the presence of idiosyncratic house price shocks, the housing asset is an inherently risky asset. Households, however, can effectively choose the risky returns to housing by taking on different levels of leverage. Since households are risk averse, for them to purchase the housing asset, at some leverage the expected return to housing, weighted by the stochastic discount factor of the household, must be greater than the return of the risk-free bond. This in turn implies a lower bound on the rental price $P_{l}$. While we do not have a theoretical characterization of that lower bound, we found in our quantitative analysis that the equilibrium rental price was such that the expected return of housing at zero leverage was always at least as high as the risk free interest rate. This implies that in our numerical analysis the following relationship holds:

$$
\left(\frac{1}{1+r_{b}}\right) \int_{\underline{\delta}}^{1}\left(1-\delta^{\prime}\right) d F\left(\delta^{\prime}\right) \geq 1-P_{l}
$$

This yields

$$
\begin{aligned}
\left(\frac{1}{1+r_{b}}\right)\left(1-E\left(\delta^{\prime}\right)\right) & \geq 1-P_{l} \text { or } \\
P_{l} & \geq \frac{r_{b}+E\left(\delta^{\prime}\right)}{1+r_{b}}
\end{aligned}
$$

which states that the rental price of housing was not smaller than the (expected) user cost of housing in equilibrium. ${ }^{9}$

In summary, we have partially characterized household behavior, developed a concise characterization of the high-dimensional equilibrium mortgage interest rate function and a derived bound for the equilibrium rental price, one of the endogenous prices to be determined in our analysis. However, to fully assess the aggregate and distributional consequences of the government interest rate subsidy a quantitative analysis is required. We will proceed to it now.

\section{Calibration}

In mapping our model to the US we focus on the period 2000-2006, that is, on a period prior to when the implicit bailout guarantee became explicit. We select some parameters exogenously, taking targets and values from the relevant literature. The remaining parameters are calibrated jointly in the model using a moment matching procedure.

\footnotetext{
${ }^{9}$ With $\gamma=1$ and $r_{w}=0$, maintaining our heuristic analysis, we would immediately obtain that the rental price of housing $P_{l}$ equals its user cost $\frac{r_{b}+E\left(\delta^{\prime}\right)}{1+r_{b}}$. In fact, what happens in this equilibrium is that households purchase houses, lever up such that they default for sure tomorrow and the houses end up in the hand of the banks. Since these are risk-neutral, and since default is fully priced into the mortgage and banks receive the full (depreciated) value of the house, banks rather than households (which are risk averse) should (from a normative perspective) and will end up owning the real estate.
} 


\subsection{Technology and Endowments}

Income process: For a continuous state $A R(1)$ process of the form

$$
\begin{aligned}
\log y^{\prime} & =\rho \log y+\left(1-\rho^{2}\right)^{0.5} \varepsilon \\
E(\varepsilon) & =0 \\
E\left(\varepsilon^{2}\right) & =\sigma_{e}^{2}
\end{aligned}
$$

we can calculate the unconditional standard deviation to be $\sigma_{e}$ and the one-period autocorrelation (persistence) to be $\rho$. Estimates for $\rho$ in the literature vary somewhat, but center around values close to 1 . Motivated by the analysis by Storesletten et al. (2004) we select $\rho=0.98$. The estimates for the standard deviation range from 0.2 to 0.4 (see Aiyagari (1994) for a discussion), and we choose $\sigma_{\varepsilon}=0.3$.

We approximate the continuous state $\mathrm{AR}(1)$ with a 5 state Markov chain using the procedure put forth by Tauchen and Hussey (1991). Section 7.3.2 in the appendix gives the exact values of the 5 income realizations, the Markov transition matrix $\pi$ and the associated invariant distribution $\Pi$.

Foreclosure technology: Two recent studies (Pennington-Cross (2004) and Campbell, Giglio and Pathak (2011)) estimate the default loss parameter $\gamma$. Pennington-Cross looks at liquidation sales revenue from foreclosed houses and compare it to a market price constructed via the OFHEO repeat sales index. Campbell, Giglio and Pathak have access to zip code level data in Massachusetts and compare foreclosed home sales to regional prices. Pennington-Cross finds that on average the loss is $22 \%$ as opposed to $27 \%$ in Campbell, Giglio and Pathak. Since Campbell, Giglio and Pathak use data from only one state, as compared to national estimates from Pennington-Cross (and their estimates are relatively close to each other), we choose the more conservative estimate and set $\gamma=0.78$.

The depreciation process: We calibrate the house value price depreciation process to attain realistic levels of default in the model while at the same generating the statistical properties of idiosyncratic house price appreciation and depreciation observed in the data. Since we are conducting a steady-state analysis, we abstract from the aggregate component of house price fluctuations and secular aggregate house price growth.

According to the Mortgage Banker Association (MBA (2006)), the quarterly foreclosure rate has been about 0.4 percent in between 2000 and 2006. Abstracting from the possibility that one house may go in and out of foreclosure multiple times within one given year, this implies that on an annual basis, banks start foreclosure proceedings on about 1.6 percent of their mortgages. The ratio of mortgages in foreclosure that eventually end in liquidation was about 25 percent in 2005, according to MBA (2006). Most homeowners avoid liquidation by either selling their property, refinancing their mortgage or just paying off the arrears. Consequently, only about 0.4 percent of mortgages actually end up in liquidation, in the way our model envisions it. Given the unusually strong home price appreciation over the 2000-06 period we view this figure as a lower bound on the long-run foreclosure rate and thus target a default rate of 0.5 percent of all mortgages. 
We target two empirical moments of house price depreciation, the mean and the standard deviation. The mean depreciation for residential housing according to the Bureau of Economic Analysis was $1.48 \%$ between 1960 and 2002 (with standard deviation 0.05\%), computed as consumption of fixed capital in the housing sector (Table 7.4.5) divided by the capital stock of residential housing. With respect to the standard deviation of idiosyncratic house price depreciation shocks, we utilize data from the Office of Federal Housing Enterprise Oversight (OFHEO). It models house prices as a diffusion process and estimates within-state and within-region annual house price volatility. The technical details can be found in the paper by Calhoun (1996). The broad range for the eight census regions is an annual volatility of $9-10 \%$ in the years 1998-2004. We use the upper bound $\sigma_{\delta}=0.10$ to account for the fact that nationwide house price volatility is slightly higher than the within-region volatility.

We found that using a log-normal distribution for house price appreciation of real estate in our model, with a mean and standard deviation above, does not generate a sufficient share of foreclosures, since, at least within the context of our model, the right tail of the distribution appears to be too thin to reproduce the empirical foreclosure target. In order to obtain more realistic levels of mortgage default we therefore use a generalized Pareto distribution whose probability distribution function is given by:

$$
f(\delta)=\frac{1}{\sigma_{\delta}}\left(1+\frac{k(\delta-\underline{\delta})}{\sigma_{\delta}}\right)^{\left(-\frac{1}{k}-1\right)}
$$

With this parametric form for the house price depreciation distribution we now have three parameters $k, \sigma_{\delta}, \underline{\delta}$ to pin down three moments: the mean depreciation rate, its standard deviation and the equilibrium share of mortgages in default that the model generates endogenously. ${ }^{10}$

Table 1: Endogenously Calibrated Parameters

\begin{tabular}{llll}
\hline Parameter & Interpretation & Value & Target \\
\hline$\sigma$ & Risk Aversion & 3.911 & Median Leverage \\
$\beta$ & Time Discount Factor & 0.919 & Risk-free Rate \\
$k$ & Pareto shape parameter & 0.7304 & Foreclosure Rate \\
$\sigma_{\delta}$ & Pareto scale parameter & 0.0077 & House price volatility \\
$\underline{\delta}$ & Pareto threshold paramter & -0.0082 & Average price depreciation \\
\hline
\end{tabular}

\subsection{Preferences}

\footnotetext{
${ }^{10}$ It is understood that, strictly speaking, all parameters determine all endogenous variables jointly. In our discussion of the parameters to be calibrated within the model we associate a parameter to the data target it affects most, quantitatively, in the model.
} 
Table 2: Exogenously Calibrated Parameters

\begin{tabular}{llll}
\hline Parameter & Interpretation & Value & Target \\
\hline$A_{h}$ & Technology Const. in Housing Constr. & 1.0 & none (normalized) \\
$\rho$ & Income Persistence & 0.98 & Storesletten at al (2004) \\
$\sigma_{e}$ & Income Variance & 0.3 & Storesletten at al (2004) \\
$\gamma$ & Foreclosure Technology & 0.78 & Pennington and Cross (2004) \\
$\theta$ & Share Parameter on Nondur. Cons. & 0.8590 & Exp. Share in BEA \\
$\phi$ & Implicit Interest Rate Subsidy & $40 \mathrm{BP}$ & CBO (2001) \\
$r_{w}$ & Mortgage administration fee & $11 \mathrm{BP}$ & \\
\hline
\end{tabular}

For the period utility function, we assume a CRRA form with a Cobb-Douglas aggregator ${ }^{11}$ between consumption and housing services.

$$
U(\tilde{c}, h)=\frac{\left(\tilde{c}^{\theta} h^{1-\theta}\right)^{1-\sigma}-1}{1-\sigma}
$$

Note that this functional form implies an indirect utility function of

$$
u\left(c ; P_{l}\right)=\frac{\Psi\left(P_{l}\right) c^{1-\sigma}-1}{1-\sigma}
$$

where $\Psi\left(P_{l}\right)=\left(\theta^{\theta}(1-\theta)^{1-\theta} P_{l}^{\theta-1}\right)^{1-\sigma}$.

We choose the parameter $\theta$ such that the share of housing in total consumption expenditures matches NIPA data, according to which this share has been steady at $14.1 \%$ over the last 40 years, with a standard deviation of only about $0.5 \%$. This yields a value of $\theta=0.8590$.

The time discount parameter $\beta$ is endogenously calibrated to match an equilibrium risk free rate of $1 \%$ in the benchmark economy. The CRRA parameter $\sigma$ is endogenously calibrated to match median household leverage in the benchmark economy. We use data from the 2004 Survey of Consumer Finances and restrict our attention to only households with heads age 50 and younger, to control for strong life-cycle trends in leverage. We then compute household leverage using data on houses owned and mortgages owed on those homes. The median leverage is calculated to be $61 \%$ from the data. The resulting preference parameters are $(\beta, \sigma)=(0.919,3.911)$.

${ }^{11}$ We could have assumed a more general CES aggregator

$$
U(\tilde{c}, h)=\frac{\left(\theta \tilde{c}^{\nu}+(1-\theta) h^{\nu}\right)^{\frac{1-\sigma}{\nu}}-1}{1-\sigma}
$$

but it is impossible to separately calibrate the parameters $\nu$ and $\theta$ from steady state relationships alone. In addition, the roughly constant expenditure share of housing over time despite significant fluctuations in the relative price of housing is consistent with the unit elasticity of substitution of the Cobb-Douglas special case $\nu \rightarrow 0$. 


\subsection{Mortgage Parameters}

For the interest rate subsidy we take the view that the pass-through of the subsidy is $100 \%$, in order to make the case for the GSE's as positive as possible. The size of the subsidy is then chosen to match the estimated implicit interest rate differential of around 40 basis points that the GSE's enjoyed during the period of their implicit guarantee by the government. Finally we pick a mortgage administration cost $r_{w}$ of 11 basis points, roughly equal to one quarter of the mortgage subsidy. This choice corresponds to an annual cost of $\$ 110$ for servicing a $\$ 100,000$ mortgage. Tables 1 and 2 summarize our parameterization of the model.

\section{Results}

\subsection{Inspecting the Mechanism}

Before analyzing the effects of the bailout policy by comparing the equilibria with and without the policy in place it is instructive to explain household behavior in the baseline economy. In figures 1 and 2 we plot the housing and leverage policy functions of households, as a function of cash at hand $a$, conditional on the lowest and highest current income realizations $y_{1}$ and $y_{5}$.

From figure 1 we observe that purchases of the housing assets are monotonically increasing in cash at hand, and figure 2 displays the fact that leverage is high (at close to 80\%) for households with little wealth. Leverage then drops quickly, as cash at hand increases, to around $61 \%$ and remains constant at that level. From the level of cash at hand for which a leverage of $61 \%$ is optimal onwards households no longer decrease leverage with increasing wealth, but start purchasing bonds as can be seen from the bond policy function displayed in figure 3. As cash at hand increases further leverage remains constant, and the holdings of the financial asset, the housing asset at mortgages rise. Proposition 4 above helps to explain why households with high wealth both borrow through high-interest mortgages and save with low-interest bearing bonds. These households want to take advantage of the high return on housing, but would like to insure against adverse house price shocks. Positive bond holdings are essentially insurance against bad $\delta$ realizations that might trigger default and thus reduce total total wealth to zero, in the absence of positive bond holdings. In order to maintain a level of consumption above that of labor income it is therefore optimal to hold bonds as insurance. Note that equation (9) determines uniquely the optimal leverage of these households, which is calculated to be $61 \%$ in the baseline model. ${ }^{12}$

\footnotetext{
${ }^{12}$ Note that since asset poor households do not buy any bonds, households allocate a larger share of their portfolios to bonds as cash at hand increases. This behavior of households may sound counterintuitive at first, but is consistent with results from the portfolio choice literature (see e.g. Cocco et al. (2005) or Haliassos and Michaelides (2001)). These papers argue that it should be households with high cash at hand that hold a higher share of their portfolio in the save asset since these households have high financial relative to human wealth (the present discounted value of future labor income). Consequently, these households expect to finance their current and future consumption primarily with capital income, whereas low cash-at-hand people tend to rely mostly on their labor income. Thus it is relatively more important for the high cash at hand people not to be exposed to a lot of financial asset return risk. In fact, since idiosyncratic labor income shocks and house depreciation shocks are uncorrelated in our model, housing is not a bad asset for hedging labor income risk (of course the bond is even better in this regard, but it also has a lower expected return).
} 


\subsection{Aggregate Effects of Removing the Subsidy}

We now turn to our evaluation of the bailout policy where we compare steady state equilibria of economies with and without a mortgage interest rates subsidy of 40 basis points. We first analyze the change in household behavior induced by the removal of the subsidy is removed, and then discuss its aggregate, distributional and welfare implications.

The main economic impact on households from removing the subsidy is to make mortgages less attractive by increasing the effective interest rate. The most notable difference in household choices can thus be seen in the leverage and bond policy functions in figures 5 and 6 respectively, where each of the two panels plots the policy functions for both cases (subsidy, no subsidy) against cash at hand, for a given current income level $y \in\left\{y_{1}, y_{5}\right\}$. We observe that for households with low levels of cash at hand the change in behavior induced by the removal of the subsidy is modest: under both policy scenarios households with little wealth take on highly leveraged mortgages and hold no bonds. As households get wealthier, however, without the subsidy leverage decreases monotonically to zero. In the absence of the mortgage interest subsidy wealthy households do not simultaneously hold bonds and mortgages, since the wedge in the interest rate between saving and borrowing (even absent default risk) increased from 11 to 51 basis points. Thus the change in the policy induces a massive reduction in leverage for wealthier households, and thus a substantial reduction in mortgage debt held by these households. As figure 4 shows, the effect on housing choice is much smaller. These two observations also imply that the removal subsidy causes a shift in the balance of the household net worth portfolio away from bonds and towards home equity as seen in figure 7. As a consequence of this general shift in households' portfolio composition, the share of bonds in the net worth portfolio of the median household declines substantially: whereas this household holds $57 \%$ of its net worth in bonds with the mortgage subsidy, this share drops to zero without the subsidy.

How the change in household behavior translates into the main macroeconomic aggregates is summarized in table 3. Aggregate mortgages taken out by households decline sharply, by $91 \%$. Despite this, the overall impact on aggregate investment into housing is actually slightly positive: the stock of housing properties increases by $2.73 \%$. Household labor income net of taxes increases by about $0.59 \%$ (that is, exactly by the amount required to finance the interest rate subsidy in general equilibrium).

The behavioral changes induced by a change in the subsidy in turn have significant general equilibrium price effects. Since the supply of housing increases, the equilibrium rental price of housing decreases, by slightly more than one percent. The equilibrium risk-free interest rate declines by 49 basis points in response to the removal of the subsidy since the demand for loans to finance house purchases collapses. Note that the effective equilibrium interest rate on borrowing, holding leverage constant, actually decreases by 9 basis points, since the 40 basis point increase due to the removal of the subsidy is more than offset by the general equilibrium effect that the reduction in the demand for loans has and that makes $r_{b}$ decline by 49 basis points. This highlights that the key margin governing household asset and portfolio choice is not the absolute cost of borrowing or return on saving, but the wedge between the borrowing and saving rate. With the subsidy (and for a mortgage with zero default risk), the difference in interest rates on saving and borrowing was 11 basis points (equal to the per dollar cost $r_{w}$ of originating and maintaining the mortgage). Without the subsidy, the effective interest rate on borrowing is 51 basis points higher than (and thus exactly double) that of saving. This reduction in the attractiveness of 
Table 3: Numerical Results: Consequences of Removing the Subsidy

\begin{tabular}{llll}
\hline Variable & Subsidy & No Subsidy & Difference \\
\hline$\%$ Sub & $40 \mathrm{bp}$ & $0 \mathrm{bp}$ & $-100 \%$ \\
$S u b / \bar{y}$ & $0.591 \%$ & $0 \%$ & $-100 \%$ \\
$P_{l}$ & 0.0281 & 0.0277 & $-1.5 \%$ \\
$r_{b}$ & $1.0 \%$ & $0.511 \%$ & $-0.489 \%$ \\
$H$ & 5.311 & 5.456 & $+2.73 \%$ \\
$M$ & 3.219 & 0.310 & $-93.7 \%$ \\
Default share & $0.51 \%$ & $0.41 \%$ & $-19.8 \%$ \\
Mean Net Worth & 5.52 & 5.445 & $-1.36 \%$ \\
Median Bond Portfolio Share & $57.29 \%$ & $-0.0 \%$ & $-100 \%$ \\
Wealth Gini & 0.4594 & 0.4625 & $0.67 \%$ \\
$\mu\left(g^{\prime}>0\right)$ & $96.79 \%$ & 96.66 & $-0.11 \%$ \\
$\mu\left(g^{\prime}>h\right)$ & $43.00 \%$ & $39.75 \%$ & $-7.56 \%$ \\
$E V^{a}$ & -0.6352 & -0.6207 & $0.8 \%$ \\
\hline
\end{tabular}

${ }^{a}$ Computed as consumption equivalent variation, that is $\left(E V_{\text {no subs }} / E V_{\text {subs }}\right)^{1 /(1-\sigma)}$

mortgage borrowing is also reflected in a decline in aggregate default rates which fall from $0.51 \%$ to $0.41 \%$ per year. Note that since default and foreclosure is costly in terms of real resources (as banks only recover a fraction $\gamma$ of the value of the home), this reduction in foreclosure rates due to the removal of the subsidy will be a nontrivial factor in the welfare evaluation of the change of the government's policy.

Given that the subsidy only benefits home owners one would expect that removing it has important consequences for the distribution of home ownership, wealth and welfare. Since the only asset in positive net supply is real estate and we have already documented that the stock of houses increases by $2.73 \%$ due to the removal of the subsidy, so does total wealth in the economy. However, median net worth falls, about $1.4 \%$. This rising gap between average and median wealth suggests that the distribution of wealth becomes more dispersed without the subsidy, which is confirmed by an increase in the Gini coefficient for (net) wealth. Figure 8 that displays the stationary wealth distributions with and without policy suggests that this is mainly due to a larger fraction of households at the borrowing constraint and a slightly fatter right tail of the wealth distribution in the scenario without the subsidy. Thus if wealth inequality is a direct concern of policy makers the removal of the subsidy is counterproductive along this dimension.

Another potential rationale for (indirectly) subsidizing mortgage interest rates on the part of the government is to increase home ownership rates in the economy. Table 3 shows that if this is indeed the ultimate goal of the government, it is successful, according to our model. The fraction of households that own some real estate, $\mu\left(g^{\prime}>0\right)$, is slightly higher with than without the interest rate subsidy. The fraction of households that own at least as much real estate as they use for their own housing service consumption, $\mu\left(g^{\prime}>h\right)$ increases more substantially, from $39 \%$ to $43 \%$ with the subsidy. Even though in our model owning real estate is somewhat disassociated 
from using that same real estate as owner occupied housing ${ }^{13}$, the fraction of households with $g^{\prime} \geq h$ is the best proxy of home ownership rates in our model, and it is negatively affected by the removal of the government subsidy.

\subsection{Welfare and Distributional Implications of the Policy}

We now turn to a discussion of the welfare consequences of the reform. Removing the mortgage interest rate subsidy increases aggregate steady state welfare, as measured by consumption equivalent variation, by a non-negligible $0.8 \%$. That is, household consumption (of both nondurables and housing services) in the steady state with the subsidy has to be increased by this percentage in all states of the world and for all households, such that a household is indifferent ex ante (that is, prior to knowing what part of the distribution he will be born into) between being born into the steady state with or without the subsidy. ${ }^{14}$

Figure 9 sheds some light on who (that is, households with which characteristics) benefits from the subsidy. The figure plots the steady state consumption equivalent gain for households with different income realizations against cash at hand. ${ }^{15}$ This plot should only be understood as a quantitative answer to the following hypothetical question: in which economy would someone with state $(a, y)$ prefer to start her life, an economy with or without subsidy? Our results indicate that the welfare gains from the subsidy are monotonically increasing in wealth, with wealth-poor households preferring to start life in the economy without subsidy while households with high wealth benefit from the subsidy. Similarly, holding wealth fixed higher current income households view the mortgage interest rate subsidy more favorably that income-poor households.

The heterogeneity in the welfare assessment of the policy across households is due to the following factors. First, the subsidy keeps interest rates on the financial assets of wealthy households high (since the subsidy fuels a stronger mortgage demand), and second, it provides these households (which invest in bonds and leverage substantially in real estate) with a direct interest rate subsidy for this investment strategy. Poorer households, on the other hand, derive a larger share of their current resources from labor income which is subject to the tax that finances the mortgage rate subsidy. Thus these households would prefer having the subsidy and the tax that comes with it removed, especially if their wealth is so low that debt-financed investment into real estate becomes suboptimal for them and thus the subsidy does not apply to these households.

We conclude (and view this as our most important normative finding) that masking the aggregate moderate welfare gains from removing the policy is a substantial heterogeneity in the welfare assessment of this policy across the population. The disagreement between households is large: the poorest member of society would pay in excess of $1 \%$ of lifetime consumption to get rid off the policy, whereas households with wealth twice the average would lose more than $1 \%$ from the same policy reform.

\footnotetext{
${ }^{13}$ In our model nothing links the housing stock $g^{\prime}$ a household owns to the housing services $h$ she consumes. These need not be the same physical houses, although it is convenient for the interpretation of our results (along the home ownership share dimension) to make that association.

${ }^{14}$ Steady state welfare comparisons can be problematic since they ignore the welfare consequences of the transition path towards the new steady state (and thus the cost of additional accumulation of physical capital or the stock of housing). In our model without capital the only transitional cost stems from building up the modest extra $2.7 \%$ of the housing stock. We therefore expect the welfare gains from moving the policy to be somewhat smaller, but still positive in the aggregate, once the transitional costs are accounted for.

${ }^{15}$ The same comments about ignoring the welfare effects along the transition apply, as before.
} 


\section{Conclusions}

In this paper we construct an equilibrium model of mortgage debt and foreclosures and use it to evaluate the aggregate and distributional consequences of a stylized bailout guarantee for GSE's in the mortgage market. We argue that this guarantee leads to excessive mortgage origination, higher leverage and larger foreclosure rates in equilibrium, compared to a world without such a policy. The steady state aggregate welfare gains from abolishing the guarantee are modest, but positive, and income and wealth-poor households would strongly benefit from such a reform.

Our environment would naturally lend itself to a quantitative evaluation of how much of the run-up in household mortgage debt can be attributed to the government's implicit and now direct involvement with the GSE's. It could also be used to study the distributional consequences of the collapse in house prices given the high leverage partially induced by this involvement. We defer this to future work.

\section{References}

[1] Acharya, V., M. Richardson, S. Van Nieuwerburgh, and L. White. Guaranteed To Fail: Freddie, Fannie, and the Debacle of U.S. Mortgage Finance, Princeton University Press, March 2011

[2] Aiyagari, S. R. (1994): "Uninsured Idiosyncratic Risk and Aggregate Saving," Quarterly Journal of Economics, 109, 659-684.

[3] Bewley, T. F. (1986). Stationary Monetary Equilibrium with a Continuum of Independently Fluctuating Consumers. In W. Hildenbrand and A. Mas-Colell Eds. Contributions to Mathematical Economics in Honor of Gerald Debreu, Amsterdam, North-Holland.

[4] Calhoun, Charles A., (1996): "OFHEO House Price Indexes: HPI Technical Description." OFHEO paper.

[5] Campbell, J.Y., S. Giglio , P. Pathak (2011): "Forced Sales and House Prices. "American Economic Review, 101(5), 2108-31.

[6] Chambers, M. , C. Garriga, and D. Schlagenhauf (2009) "The Loan Structure and Housing Tenure Decisions in an Equilibrium Model of Mortgage Choice," Review of Economic Dynamics, 444-468.

[7] Chatterjee, S., D. Corbae, M. Nakajima and V. Rios-Rull (2007): "A Quantitative Theory of Unsecured Consumer Credit with Risk of Default," Econometrica, 75, 1525-1590.

[8] Chatterjee, S. and B. Eyigungor (2011): "Foreclosures and House Price Dynamics: A Quantitative Analysis of the Mortgage Crisis and the Foreclosure Prevention Policy," Working paper, Federal Reserve Bank of Philadelphia.

[9] Clausen, A. and C. Strub. "Envelop Theorems for Non-Smooth and Non-Concave Optimization, ". Working paper, University of Pennsylvania. 
[10] Cocco, J., F. Gomes and P. Maenhout (2005): "Consumption and Portfolio Choice over the Life-Cycle," Review of Financial Studies, 18(2), 491-533..

[11] Congressional Budget Office (CBO) (2001): Federal Subsidies and the Housing GSE's, Washington, D.C.

[12] Corbae, D. and E. Quintin (2009): "Mortgage Innovation and the Foreclosure Boom," Working paper, University of Texas.

[13] Blinder, A., M., Flannery, J. Kamihachi, (2004). "The Value of Housing-Related Government Sponsored Enterprises: A Review of a Preliminary Draft Paper by Wayne Passmore. "Fannie Mae Papers, vol III, Issue 2.

[14] Fernandez-Villaverde, J. and D. Krueger (2011): "Consumption and Saving over the Life Cycle: How Important are Consumer Durables?" forthcoming in Macroeconomic Dynamics.

[15] Foote, C., K. Gerardi, L. Goette and P. Willen (2009): "Reducing Foreclosures," NBER Macroeconomics Annual 2009, forthcoming.

[16] Frame, Scott and Larry Wall (2002a): "Financing Housing through Government-Sponsored Enterprises" Economic Review, Federal Reserve Bank of Atlanta, First Quarter 2002.

[17] Frame, Scott and Larry Wall (2002b): "Fannie Mae's and Freddie Mac's Voluntary Initiatives: Lessons from Banking". Economic Review, Federal Reserve Bank of Atlanta, First Quarter 2002.

[18] Garriga, C. and D. Schlagenhauf (2009): "Home Equity, Foreclosures, and Bailouts," Working paper, Federal Reserve Bank of St. Louis.

[19] Gerardi, K., H. Rosen and P. Willen (2009): "The Impact of Deregulation and Financial Innovation on Consumers: The Case of the Mortgage Market, " Journal of Finance, forthcoming

[20] Gervais, M. (2002): "Housing Taxation and Capital Accumulation," Journal of Monetary Economics, 49, 1461-1489.

[21] Gruber, J. and R. Martin (2003): "Precautionary Savings and the Wealth Distribution with a Durable Good," International Finance Discussion Papers 773, Federal Reserve Board.

[22] Gourinchas, P. and J. A. Parker (2002). Consumption over the Life Cycle. Econometrica, 70(1), 47-89.

[23] Haliassos, M. and A. Michaelides (2003): "Portfolio Choice and Liquidity Constraints," International Economic Review, 44, 143-78.

[24] Huggett, M. (1993): "The Risk-Free Rate in Heterogeneous-Agent Incomplete-Insurance Economies," Journal of Economic Dynamics and Control, 17, 953-969.

[25] Krainer, J., S. LeRoy and Munpyung O (2009): "Mortgage Default and Mortgage Valuation," Federal Reserve Bank of San Francisco Working Paper 2009-20. 
[26] Livshits, I., J. MacGee and M. Tertilt (2007): "Consumer Bankruptcy: A Fresh Start," American Economic Review, Vol. 97(1), 402-418.

[27] Mian, A, A. Sufi and F. Trebbi (2011): "Foreclosures, House Prices, and the Real Economy," NBER Working Paper 16685.

[28] Passmore, W., S. Sherlund and G. Burgess. (2005): "The Effect of Housing Government Sponsored Enterprises on Mortgage Rates." Real Estate Economics, 33(3), 427-463.

[29] Pennington-Cross, Anthony (2006): "The Value of Foreclosed Property: House Prices, Foreclosure Laws, and Appraisals," Journal of Real Estate Research, Vol. 28(2), 193-214.

[30] Ríos-Rull, J.V., and V. Sánchez-Marcos (2008) "An Aggregate Economy with Different House Sizes, "Journal of the European Economic Association, 6 (2-3), pp 705-714.

[31] Stokey, N. and R. Lucas, with E. Prescott (1989): "Recursive Methods in Economic Dynamics," Harvard University Press, Cambridge.

[32] Storesletten, K., C. Telmer, and A. Yaron (2004): "Consumption and Risk Sharing over the Life Cycle," Journal of Monetary Economics, 51, 609-633.

[33] Tauchen, G. and R. Hussey (1991): "Quadrature-Based Methods for Obtaining Approximate Solutions to Nonlinear Asset Pricing Models," Econometrica, Vol. 59, No. 2. (Mar., 1991), pp. 371-396. 


\section{Theoretical Appendix}

\subsection{Endogenous Upper Bound on Leverage}

In this section we will construct a proof of Proposition 2 in the main text.

Proof. In order to prove the statement, we will first show that there exists a $\kappa^{*}$ that maximizes the contemporaneous resources available to the household. Then we will show that in equilibrium households will only chose values of leverage less than $\kappa^{*}$ and that that value is strictly less than the leverage which leads to certain default.

First, consider the period budget constraint:

$$
c+b P_{b}+h P_{l}+g-m P_{m}(g, m)=a+g P_{l}
$$

This can be rewritten as:

$$
g\left[1-P_{l}-\kappa P_{m}(g, m)\right]=a-c-h P_{l}-b P_{b}
$$

For a fixed $g>0$, we can calculate the value of $m$ that will generate the maximal amount of resources available today:

$$
\begin{aligned}
m^{*} \in \arg \min _{0 \leq m \leq g(1-\underline{\delta})} & {\left[g\left[1-P_{l}-\kappa P_{m}(g, m)\right]\right.} \\
\Leftrightarrow m^{*} \in \arg \min _{0 \leq m \leq g(1-\underline{\delta})} & -m P_{m}(g, m)
\end{aligned}
$$

Note that the upper bound on $m$ is the leverage that will result in default for sure in the second period. It can be shown that borrowing above this level does not increase resources available today. Further, this compactifies and choice space and guarantees the pricing function is differentiable on the interior. The FOC for this program is:

$$
-P_{m}(\kappa)-m \frac{\partial P_{m}(\kappa)}{\partial \kappa} \frac{\partial \kappa}{\partial m}+\lambda=0
$$

where $\lambda \geq 0$ is the Lagrange multiplier on the upper constraint (the lower bound trivially is not binding as long as $\mathbb{E}[\delta]<1 \Rightarrow P_{m}>0$ ). The SOC (exists to the differentiability of $f(\delta)$ ) is:

$$
-\frac{1}{g}\left[2 \frac{\partial P_{m}(\kappa)}{\partial \kappa}+\kappa \frac{\partial^{2} P_{m}(\kappa)}{\partial \kappa^{2}}\right]
$$

In order to simplify these conditions, consider the mortgage pricing function, $P_{m}\left(\frac{m}{g}\right)$ given by:

$$
P_{m}(\kappa)=\frac{1}{1+r_{b}+p}\left\{F(1-\kappa)+\frac{\gamma}{\kappa} \int_{1-\kappa}^{\bar{\delta}}(1-\delta) d F(\delta)\right\}
$$

As long as $\delta$ has a continuous pdf (guaranteed because $F \in \mathcal{C}^{2}$ ), we can apply Leibnitz's rule to obtain: 


$$
\begin{aligned}
\frac{\partial P_{m}(\kappa)}{\partial \kappa} & =\frac{1}{1+r_{b}+p} \times \\
& \left\{-f(1-\kappa)-\frac{\gamma}{\kappa^{2}} \int_{1-\kappa}^{\bar{\delta}}(1-\delta) d F(\delta)+\frac{\gamma}{\kappa}(-1)(-1)(1-(1-\kappa)) f(1-\kappa)\right\} \\
& =\frac{1}{1+r_{b}+p}\left\{(\gamma-1) f(1-\kappa)-\frac{\gamma}{\kappa^{2}} \int_{1-\kappa}^{\bar{\delta}}(1-\delta) d F(\delta)\right\}
\end{aligned}
$$

We can simplify the FOC by substituting in our prior calculations to obtain:

$$
\begin{aligned}
0 & =P_{m}\left(\kappa^{*}\right)+\kappa^{*} \frac{1}{1+r_{b}+p}\left\{(\gamma-1) f\left(1-\kappa^{*}\right)-\frac{\gamma}{\kappa^{* 2}} \int_{1-\kappa^{*}}^{\bar{\delta}}(1-\delta) d F(\delta)\right\}-\lambda \\
& =F\left(1-\kappa^{*}\right)+\frac{\gamma}{\kappa^{*}} \int_{1-\kappa^{*}}^{\bar{\delta}}(1-\delta) d F(\delta)+(\gamma-1) \kappa^{*} f\left(1-\kappa^{*}\right)-\frac{\gamma}{\kappa^{*}} \int_{1-\kappa^{*}}^{\bar{\delta}}(1-\delta) d F(\delta)-\lambda \\
& =F\left(1-\kappa^{*}\right)+(\gamma-1) \kappa^{*} f\left(1-\kappa^{*}\right)-\lambda
\end{aligned}
$$

Notice that the first term goes to zero as we approach the upper constraint on leverage. The second term is weakly negative (since $\gamma<1$ and $f \geq 0$ ). Thus, since we have constructed our maximization problem to guarantee that $\lambda \geq 0$, the only admissible value is $\lambda=0$. Thus, we can characterize interior value of leverage which satisfies the FOC by the implicit equation:

$$
\kappa^{*}=\frac{F\left(1-\kappa^{*}\right)}{(1-\gamma) f\left(1-\kappa^{*}\right)}
$$

A solution to this implicit equation exists and is unique on $(0, \bar{\kappa})$. To see this rewrite the implicit equation as:

$$
\frac{1}{1-x}=(1-\gamma) \frac{f(x)}{F(x)}
$$

for $x \in(\underline{\delta}, 1)$. The RHS is strictly increasing in $x$, and takes values from $[1 /(1-\underline{\delta}), \infty)$. The LHS is decreasing and also unbounded above (both coming from log-concavity of $F$ ). Thus, from a standard fixed-point theorem in $\mathbb{R}$, there exists an $x$ in that interval which satisfies the equation and it is unique.

Now that we have found an interior solution to the FOC, we must check the SOC, which simplifies to:

$$
-\frac{1}{g\left(1+r_{b}+p\right)}\left\{(\gamma-2) f(1-\kappa)+(1-\gamma) \kappa f^{\prime}(1-\kappa)\right\}
$$

If the SOC is strictly positive at $\kappa^{*}$, the FOC condition will be necessary and sufficient for a minimum, and thus will characterize the leverage which yields the maximal amount of contemporaneous resources. Log-concavity of $F(\delta)$ is sufficient for the SOC to be strictly positive. To 
see this, first note that log-concavity implies $f^{\prime 2}<0$. Using this fact we can show:

$$
\begin{aligned}
f^{\prime} & <\frac{f}{F} f \\
\Rightarrow f^{\prime}\left(1-\kappa^{*}\right) & <\frac{f\left(1-\kappa^{*}\right)}{F\left(1-\kappa^{*}\right)} f\left(1-\kappa^{*}\right) \\
\Rightarrow(1-\gamma) \kappa^{*} f^{\prime}\left(1-\kappa^{*}\right) & <f\left(1-\kappa^{*}\right)
\end{aligned}
$$

where the last inequality comes from equation (19). Now, this last inequality, along with the fact that $\gamma<1$ and $f \geq 0$ implies that the SOC at $\kappa^{*}$ will be strictly positive. Thus, we have shown that our interior $\kappa^{*}$ is indeed a maximum.

Now that we've shown the existence of $\kappa^{*}$ to prove the first statement, suppose by way of contradiction that a household has chosen an affordable allocation $\{c, h, b, g, m\}$ such that $\kappa>\kappa^{*}$. Consider another allocation $\left\{c^{\prime}, h^{\prime}, b^{\prime}, g^{\prime}, m^{\prime}\right\}$, where $h^{\prime}=h, b^{\prime}=b, g^{\prime}=g$ and $m^{\prime}$ is such that $\frac{m^{\prime}}{g^{\prime}}=\kappa^{*}$ and $c^{\prime}=c+m^{\prime} P_{m}\left(\kappa^{*}\right)-m P_{m}(\kappa)$. Note that this new allocation is affordable, $m^{\prime} P_{m}\left(\kappa^{*}\right)>m P_{m}(\kappa) \Rightarrow c^{\prime}>c$ (from above) and cash-at-hand in the next period will be weakly greater in all possible states under the primed allocation than the original (since $b=b^{\prime}, g=g^{\prime}$ and $\left.m^{\prime}<m, b+\max ((1-\delta) g-m, 0) \leq b^{\prime}+\max \left((1-\delta) g^{\prime}-m^{\prime}, 0\right)\right)$. Thus, from the strict monotonicity of the utility function, the primed allocation yields strictly higher period utility and weakly higher continuation value, and thus is strictly preferred to the original.

\subsection{Existence, Uniqueness and Characterization of the Value Func- tion}

\subsubsection{Definitions}

First we need some definitions. Let the $M \subset \mathbb{R}_{+}$mortgage choice set, $B \subset \mathbb{R}_{+}$be the bond choice set, $G \subset \mathbb{R}_{+}$be the housing choice set, $C \subset \mathbb{R}_{+}$the consumption expenditure choice set. The state variable, cash-at-hand, $a \in A \subset \mathbb{R}_{+}$. Income, $y \in Y$, where $Y$ is a finite set. We define the budget correspondence $\Gamma: A \rightarrow C \times B \times G \times M$ as:

$$
\Gamma(a)=\left\{(c, b, g, m) \in C \times B \times G \times M: c+b P_{b}+g\left[1-P_{l}\right]-m P_{m}(g, m) \leq a, \quad m \leq g \tilde{\kappa}\right\}
$$

where $\tilde{\kappa}$ is the endogenous maximal leverage characterized previously.

We can write down our Bellman equation ${ }^{16}$.

$$
v(a, y)=\max _{x \in \Gamma(a)} u\left(c ; P_{l}\right)+\beta \sum_{y^{\prime} \in Y} \pi\left(y^{\prime} \mid y\right) \int v\left(\phi\left(b^{\prime}, g^{\prime}, m^{\prime}, \delta^{\prime}, y^{\prime}\right), y^{\prime}\right) d F\left(\delta^{\prime}\right)
$$

where $x=\left(c, b^{\prime}, g^{\prime}, m^{\prime}\right)$ and $\phi\left(b^{\prime}, g^{\prime}, m^{\prime}, \delta^{\prime}, y^{\prime}\right)=b^{\prime}+\max \left(\left(1-\delta^{\prime}\right) g^{\prime}-m^{\prime}, 0\right)+(1-\tau) y^{\prime}$. We can now define our operator, $T: A \times Y \rightarrow A \times Y$ as:

$$
T v(a, y)=\max _{x \in \Gamma(a)} u\left(c ; P_{l}\right)+\beta \sum_{y^{\prime} \in Y} \pi\left(y^{\prime} \mid y\right) \int v\left(\phi\left(b^{\prime}, g^{\prime}, m^{\prime}, \delta^{\prime}, y^{\prime}\right), y^{\prime}\right) d F\left(\delta^{\prime}\right)
$$

\footnotetext{
${ }^{16}$ We will show in the next section that $\Gamma$ is compact valued, so the maximum of the program will be obtained, justifying our use of the max-operator as opposed to the sup-operator.
} 
With our definitions in hand, we proceed to discuss the properties of the budget correspondence and our operator.

\subsubsection{Properties of $\Gamma$ and $T$}

We begin by establishing properties of $\Gamma$. First, it is non-empty $(0 \in \Gamma(a))$ and monotone. Given prices that satisfy ${ }^{17} 1-P_{l}-\kappa P_{m}(\kappa)>0 \forall \kappa \in[0, \tilde{\kappa}]$, we can show that $\Gamma$ is also continuous and compact valued. To prove this we endeavor to apply Theorems 3.4 and 3.5 from Stokey \& Lucas (1989). We will show that the conditions for these two theorems are met by proving two lemmas.

Lemma 1 The graph of $\Gamma, G=\{(a, c, b, g, m) \in A \times C \times B \times G \times M:(c, b, g, m) \in \Gamma(a)\}$ is closed, and for any bounded set $\hat{A} \subset A, \Gamma(\hat{A})$ is bounded.

Proof. To show that the graph is closed, take a sequence $\left\{\left(a_{n}, c_{n}, b_{n}, g_{n}, m_{n}\right)\right\}_{n=0}^{\infty}$ such that $\left(c_{n}, b_{n}, g_{n}, m_{n}\right) \in \Gamma\left(a_{n}\right)$ for all $n$ that converges to $\left(a^{*}, c^{*}, b^{*}, g^{*}, m^{*}\right)$. Suppose that $\left(c^{*}, b^{*}, g^{*}, m^{*}\right) \notin$ $\Gamma\left(a^{*}\right)$. This implies either $c^{*}+b^{*} P_{b}+g^{*}\left[1-P_{l}\right]-m^{*} P_{m}\left(g^{*}, m^{*}\right)>a^{*}$ or $m^{*}>g^{*} \tilde{\kappa}$. However, since everything is continuous here, that implies that there exists some $N$ such that ones of the inequalities is also violated for $\left(a_{N}, c_{N}, b_{N}, g_{N}, m_{N}\right)$, but that implies $\left(c_{N}, b_{N}, g_{N}, m_{N}\right) \notin \Gamma\left(a_{N}\right)$, a contradiction.

To show that $\Gamma(\hat{A})$ is bounded, let $\hat{a}=\sup \hat{A}$. Since $\Gamma$ is monotone, if $\Gamma(\hat{a})$ is bounded, $\Gamma(\hat{A})$ will be bounded. Now, observe that $0 \leq c \leq a, 0 \leq b \leq a / P_{b}$. To prove that $g$ is bounded above is equivalent to showing $\forall a \in \mathbb{R}_{+} \exists \bar{g} \geq 0$ s.t. $\forall g>\bar{g},(c, b, g, m) \notin \Gamma(a)$. We will construct such a candidate $\bar{g}$. We propose $\bar{g}(a)$ such that $\bar{g}(a)=a /\left[1-P_{l}-\tilde{\kappa} P_{m}(\tilde{\kappa})\right]$, where $\tilde{\kappa}$ is the endogenous leverage limit. Now, suppose by way of contradiction that there was an allocation $(c, b, g, m) \in \Gamma(a)$ with $g>\bar{g}(a)$. This implies that:

$$
\begin{aligned}
c+b P_{b}+g\left[1-P_{l}-\kappa P_{m}(g, m)\right] & \leq a \\
\Rightarrow c+b P_{b}+g\left[1-P_{l}-\kappa^{*} P_{m}\left(g, m^{*}\right)\right] & \leq a \\
\Rightarrow g & \leq \bar{g}-\frac{c+b P_{b}}{1-P_{l}-\kappa^{*} P_{m}\left(g, m^{*}\right)} \\
\Rightarrow g & \leq \bar{g} \Rightarrow \Leftarrow
\end{aligned}
$$

Thus, for any $a, \Gamma(a)$ is bounded $\Rightarrow \Gamma(\hat{a})$ is bounded $\Rightarrow \Gamma(\hat{A})$ is bounded.

Lemma 2 The graph of $\Gamma, G$, is convex, and for any bounded set $\hat{A} \subset A$, there exists a bounded set $\hat{X} \subset C \times B \times G \times M$ such that $\Gamma(a) \cap \hat{X} \neq \emptyset$ for all $a \in \hat{A}$.

Proof. The second part of the lemma is trivially satisfied by letting $\hat{X}=\{(0,0,0,0)\}$.

In order to show convexity we need to establish that $-m P_{m}(m, g)$ is convex, which will make $c+b P_{b}+g\left[1-P_{l}\right]-m P_{m}(g, m)$ convex in $c, b, g, m$, guaranteeing that the inequality constraint will hold for convex combinations. Consider the Hessian for $-m P_{m}(m, g)$ :

$$
\mathcal{D}^{2}\left(-m P_{m}(m, g)\right)=\left[\begin{array}{cc}
-\frac{1}{g}\left(2 P_{m}^{\prime}+\kappa P_{m}^{\prime \prime}\right) & \frac{\kappa}{g}\left(2 P_{m}^{\prime}+\kappa P_{m}^{\prime \prime}\right) \\
\frac{\kappa}{g}\left(2 P_{m}^{\prime}+\kappa P_{m}^{\prime \prime}\right) & -\frac{\kappa^{2}}{g}\left(2 P_{m}^{\prime}+\kappa P_{m}^{\prime \prime}\right)
\end{array}\right]
$$

\footnotetext{
${ }^{17}$ This is a no-arbitrage condition on the relation between the interest rate and rental rate, and thus will be true in any equilibrium
} 
The Hessian is singular, in order to show that the matrix is positive semi-definite, and hence that $-m P_{m}(m, g)$ is convex, we only need to show that the two diagonal elements are positive. Thus, we need to show that $2 P_{m}^{\prime}+\kappa P_{m}^{\prime \prime} \leq 0$. From before we know that:

$$
2 P_{m}^{\prime}+\kappa P_{m}^{\prime \prime}=\frac{1}{1+r_{b}+p}\left\{(\gamma-2) f(1-\kappa)+(1-\gamma) \kappa f^{\prime}(1-\kappa)\right\}
$$

Focusing on:

$$
(\gamma-2) f(1-\kappa)+(1-\gamma) \kappa f^{\prime}(1-\kappa)
$$

We again employ the maintained assumption of log-concavity of $F(\delta)$ to show:

$$
\begin{aligned}
\frac{f(1-\tilde{\kappa})}{F(1-\tilde{\kappa})} & \geq \frac{f(1-\kappa)}{F(1-\kappa)} \quad \forall \kappa \in[0, \tilde{\kappa}] \\
\Rightarrow f^{\prime}(1-\kappa) & <\frac{f(1-\tilde{\kappa})}{F(1-\tilde{\kappa})} f(1-\kappa) \quad \forall \kappa \in[0, \tilde{\kappa}] \\
\Rightarrow f^{\prime}(1-\kappa) & <\frac{1}{(1-\gamma) \tilde{\kappa}} f(1-\kappa) \quad \forall \kappa \in[0, \tilde{\kappa}] \\
\Rightarrow f^{\prime}(1-\kappa) & <\frac{1}{(1-\gamma) \kappa} f(1-\kappa) \quad \forall \kappa \in[0, \tilde{\kappa}] \quad \text { since } f>0 \\
(1-\gamma) \kappa f^{\prime}(1-\kappa) & <f(1-\kappa) \quad \forall \kappa \in[0, \tilde{\kappa}]
\end{aligned}
$$

which guarantees that (30) is negative, which gives that the diagonal elements are non-negative, combined with the fact that the determinant is zero, yields that the Hessian is positive semidefinite on $\kappa \in[0, \tilde{\kappa}]$, which is equivalent to $g \in[0, \bar{g}(a)], m \in[0, g \tilde{\kappa}]$. Thus, we've established convexity of $G$.

These two lemmas, combined with Stokey \& Lucas theorems 3.4 and 3.5, guarantee that $\Gamma$ is compact valued, u.h.c and l.h.c. Since we are dealing with the simplified household problem, we need to show some properties about utility function over consumption expenditure.

Lemma $3 u\left(c ; P_{l}\right)$ is continuous, strictly concave, strictly increasing.

Proof. Take $c_{1}, c_{2}>0$ and $c_{\theta}=\theta c_{1}+(1-\theta) c_{2}$ for $\theta \in(0,1) . u\left(c_{i} ; P_{l}\right) \equiv U\left(\tilde{c}_{i}, h_{i}\right)$ where $\tilde{c}_{i}$ and $h_{i}$ are from the maximizers. From the strict concavity of $U$, we know that

$$
\begin{aligned}
\theta U\left(\tilde{c_{1}}, h_{1}\right)+(1-\theta) U\left(\tilde{c_{2}}, h_{2}\right) & <U\left(\theta \tilde{c_{1}}+(1-\theta) \tilde{c_{2}}, \theta h_{1}+(1-\theta) h_{2}\right) \\
& \leq U\left(\tilde{c_{\theta}}, h_{\theta}\right)
\end{aligned}
$$

where the first inequality comes from the strict concavity of $U$ and the second from the fact that $\theta \tilde{c_{1}}+(1-\theta) \tilde{c_{2}}+P_{l}\left(\theta h_{1}+(1-\theta) h_{2}\right)=\theta c_{1}+(1-\theta) c_{2}=c_{\theta}$, thus it's a feasible choice for the maximization for $u\left(c_{\theta} ; P_{l}\right)$, and by definition of a max. Continuity and strict monotonicity follow from the properties of $U$.

Since we have assumed that the utility function is unbounded from below, we use a similar argument to Chatterjee et al. (2007) to establish the existence and uniqueness of the value function. Let $\mathcal{V}$ be the set of all continuous functions $v: A \times Y \rightarrow \mathbb{R}$, such that: 


$$
\begin{gathered}
v(a, y) \in\left[\frac{u\left((1-\tau) y_{\min } ; P_{l}\right)}{1-\beta}, \frac{\bar{u}}{1-\beta}\right] \\
u\left((1-\tau) y_{\min } ; P_{l}\right)+\beta \sum_{y^{\prime} \in Y} \pi\left(y^{\prime} \mid y\right) v\left((1-\tau) y^{\prime}, y^{\prime}\right)>u\left(0 ; P_{l}\right)+\frac{\beta \bar{u}}{1-\beta}
\end{gathered}
$$

Lemma $4 \mathcal{V}$ is non-empty. $(\mathcal{V},\|\cdot\|)$ is a complete metric space, where $\|\cdot\|$ is the sup-norm.

Proof. Take any constant function $v_{0}$ satisfying (38). $v_{0}$ is continuous and satisfies (39) by the assumption that $u$ is unbounded below. In order to show that $(\mathcal{V},\|\cdot\|)$ is complete, first note that $(\mathcal{C},\|\cdot\|)$ is complete, where $\mathcal{C}$ is the set of continuous functions from $A \times Y \rightarrow \mathbb{R}$. First note that $\mathcal{V} \subset \mathcal{C}$, and thus it is sufficient to show that $\mathcal{V}$ is a closed subset of $\mathcal{C}$. So take any sequence of functions $\left\{v_{n}\right\}_{n=0}^{\infty} \in \mathcal{V}$ such that $v_{n} \rightarrow v^{*}$. We need to show that $v^{*} \in \mathcal{V}$. Suppose not, i.e. $v^{*} \notin \mathcal{V}$. Then either $v^{*}$ is not continuous, or (38) or (39) was violated. Continuity is preserved because $v_{n} \rightarrow v^{*}$ uniformly given the sup-norm. If (38) is violated, then there must exist some $N$ such that it is also violated for $v_{N}$, contradicting that $v_{N} \in \mathcal{V}$. Finally, given (38), (39) is satisfied by the assumption of unboundedness of $u$ from below.

Now we need to show that for all $v \in \mathcal{V}, T v \in \mathcal{V}$. Thus, we need to establish that $T$ preserves continuity, (38) and (39). To show that $T$ preserves continuity, first note that $\phi\left(b^{\prime}, g^{\prime}, m^{\prime}, \delta^{\prime}, y^{\prime}\right)$ is a continuous function. Thus $v(\phi, y)$ is also continuous, because the composition of continuous functions is continuous. Further, continuity is preserved by integration, thus $\sum_{y^{\prime} \in Y} \pi\left(y^{\prime} \mid y\right) \int v\left(\phi\left(b^{\prime}, g^{\prime}, m^{\prime}, \delta^{\prime}, y^{\prime}\right), y^{\prime}\right) d F\left(\delta^{\prime}\right)$ is also continuous. This implies that:

$$
u\left(c ; P_{l}\right)+\beta \sum_{y^{\prime} \in Y} \pi\left(y^{\prime} \mid y\right) \int v\left(\phi\left(b^{\prime}, g^{\prime}, m^{\prime}, \delta^{\prime}, y^{\prime}\right), y^{\prime}\right) d F\left(\delta^{\prime}\right)
$$

is a continuous function in $c, b^{\prime}, g^{\prime}, m^{\prime}$ on $C \times B \times G \times M$. That, combined with the previously established fact that $\Gamma$ is compact valued and continuous allows us to assert the continuity of $T v$ from the Theorem of the Maximum. To show that (38) is preserved, note that $u\left(c ; P_{l}\right)$ is bounded above by $\bar{u}$, thus $T v \leq \bar{u}+\beta \bar{u} /(1-\beta)=\bar{u} /(1-\beta)$. Further, choosing a consumption expenditure of $c=(1-\tau) y_{\min }$ is feasible in all periods, thus $T v \geq u\left((1-\tau) y_{\min } ; P_{l}\right)+\beta u\left((1-\tau) y_{\min } ; P_{l}\right) /(1-\beta)=$ $u\left((1-\tau) y_{\min } ; P_{l}\right) /(1-\beta)$. This result, combined with The assumption that $u\left(0 ; P_{l}\right)=-\infty$ guarantees that $T v$ satisfies (39). Thus $T \mathcal{V} \subset \mathcal{V}$.

And now the final lemma necessary to prove our main result:

Lemma 5 The operator $T$ is a contraction with modulus $\beta$.

Proof. To prove this we will show that $T$ satisfies monotonicity and discounting and then apply Blackwell's (Stokey \& Lucas Theorem 3.3).

Take $v, w \in \mathcal{V}$ such that $v(a, y) \leq w(a, y)$ for all $(a, y) \in A \times Y$. We want to show that $T v \leq$ $T w$. By the definition of $T$ and the fact that $\sum_{y^{\prime} \in Y} \pi\left(y^{\prime} \mid y\right) \int v\left(a^{\prime}, y^{\prime}\right) d F\left(\delta^{\prime}\right) \leq \sum_{y^{\prime} \in Y} \pi\left(y^{\prime} \mid y\right) \int w\left(a^{\prime}, y^{\prime}\right) d F\left(\delta^{\prime}\right)$,

$T v \leq T w$. To show discounting take any $\gamma \in \mathbb{R}_{+}, T(v+\gamma)=T v+\beta \sum_{y^{\prime} \in Y} \pi\left(y^{\prime} \mid y\right) \int \gamma d F\left(\delta^{\prime}\right)=$ $T v+\beta \gamma$. Thus, from Blackwell's, $T$ is a contraction mapping. 
Proposition 5 Under the maintained assumptions on $u$ and the assumption that $F(\delta)$ is $\mathcal{C}^{2}$ and log-concave, there exists a unique $v^{*} \in \mathcal{V}$ such that $T v^{*}=v^{*}$. Furthermore, $v^{*}$ is strictly increasing in a.

Proof. From Lemma's 5, 4 and the contraction mapping theorem, there exists a unique $v^{*} \in \mathcal{V}$ such that $T v^{*}=v^{*}$. In order to show that $v^{*}$ is increasing in $a$ we appeal to the monotonicity of $\Gamma$ and the strict monotonicity of $u\left(c ; P_{L}\right)$. Take $a, a^{\prime} \in A$ such that $a<a^{\prime}$. We want to show $v^{*}(a, y)<v^{*}\left(a^{\prime}, y\right)$.

$$
\begin{aligned}
v^{*}(a, y) & =\max _{x \in \Gamma(a)} u\left(c ; P_{l}\right)+\beta \sum_{y^{\prime} \in Y} \pi\left(y^{\prime} \mid y\right) v^{*}\left(\phi\left(b^{\prime}, g^{\prime}, m^{\prime}, \delta^{\prime}, y^{\prime}\right), y^{\prime}\right) d F\left(\delta^{\prime}\right) \\
& =u\left(c^{*} ; P_{l}\right)+\beta \sum_{y^{\prime} \in Y} \pi\left(y^{\prime} \mid y\right) v^{*}\left(\phi\left(b^{\prime *}, g^{\prime *}, m^{\prime *}, \delta^{\prime}, y^{\prime}\right), y^{\prime}\right) d F\left(\delta^{\prime}\right) \\
& <u\left(c^{*}+a^{\prime}-a ; P_{l}\right)+\beta \sum_{y^{\prime} \in Y} \pi\left(y^{\prime} \mid y\right) v^{*}\left(\phi\left(b^{\prime *}, g^{\prime *}, m^{\prime *}, \delta^{\prime}, y^{\prime}\right), y^{\prime}\right) d F\left(\delta^{\prime}\right) \\
& \leq \max _{x \in \Gamma\left(a^{\prime}\right)} u\left(c ; P_{l}\right)+\beta \sum_{y^{\prime} \in Y} \pi\left(y^{\prime} \mid y\right) v^{*}\left(\phi\left(b^{\prime}, g^{\prime}, m^{\prime}, \delta^{\prime}, y^{\prime}\right), y^{\prime}\right) d F\left(\delta^{\prime}\right) \\
& =v^{*}\left(a^{\prime}, y\right)
\end{aligned}
$$

where the third line comes from the strict monotonicity of $u$. The fourth line comes from the fact that $a^{\prime}-a>0$ and the fact that if $\left(c^{*}, b^{\prime *}, g^{\prime *}, m^{\prime *}\right) \in \Gamma(a) \Rightarrow\left(c^{*}+a^{\prime}-a, b^{* *}, g^{\prime *}, m^{\prime *}\right) \in \Gamma\left(a^{\prime}\right)$.

\subsubsection{Characterization}

In this section we prove Proposition 4.

Proof. We seek to apply theorem 3 of Clausen and Strub (2011). Consider re-writing the value function as follows:

$$
V(b, g, m, \delta, d, y)=\max _{x \in \Gamma(a), d^{\prime} \in\{0,1\}} u\left(c ; P_{l}\right)+\beta \sum_{y^{\prime} \in Y} \pi\left(y^{\prime} \mid y\right) V\left(b^{\prime}, g^{\prime}, m^{\prime}, \delta^{\prime}, d^{\prime}, y^{\prime}\right) d F\left(\delta^{\prime}\right)
$$

where $x$ and $\Gamma$ are defined as before, but now

$$
a=b^{\prime}+y^{\prime}+\left(1-d^{\prime}\right)\left[\left(1-\delta^{\prime}\right) g^{\prime}-m^{\prime}\right]
$$

where we explicitly model the foreclosure decision with $d^{\prime}$. Since, as we showed above, the value function is finite and if the utility function is differentiable then it will also be differentiable with respect to $b, g, m$ holding $g^{\prime}, b^{\prime}, m^{\prime}, d, d^{\prime}$ constant, and differentiable with respect to $g^{\prime}, b^{\prime}, m^{\prime}$ holding $b, g, m, d, d^{\prime}$ constant (based on how it is defined above). Then, we can conclude that if $\left(g^{\prime}, b^{\prime}, m^{\prime}, d^{\prime}\right)$ is an optimal choice at $b, g, m, d, \delta$ and $g^{\prime}, b^{\prime}, m^{\prime}>0$, then $V$ will be differentiable in $g^{\prime}, b^{\prime}, m^{\prime}$ for all $\delta^{\prime}$. Taking first order conditions and rearranging yields the characterization in Proposition 4 . 


\subsection{Computational Appendix}

\subsubsection{Simplification of the Household Problem}

For computation it will be convenient to split the household maximization problem into a portfolio choice problem in which the household chooses how much to invest in bonds and houses and how much of the house to finance, and into a standard intertemporal consumption-saving problem. Define

$$
x^{\prime}=b^{\prime} P_{b}+g^{\prime}\left[1-P_{l}\right]-m^{\prime} P_{m}\left(\kappa^{\prime}\right) .
$$

Then the consumption-savings problem reads as

$$
v(a, y)=\max _{0 \leq x^{\prime} \leq a}\left\{u\left(a-x^{\prime} ; P_{l}\right)+\beta \sum_{y^{\prime}} \pi\left(y^{\prime} \mid y\right) w\left(x^{\prime}, y^{\prime}\right)\right\}
$$

where the value of saving $x^{\prime}$ units is given by

$$
\begin{aligned}
w\left(x^{\prime}, y^{\prime}\right)= & \max _{b^{\prime}, g^{\prime}, m^{\prime} \geq 0} \int_{\underline{\delta}}^{\infty} v\left(a^{\prime}, y^{\prime}\right) d F\left(\delta^{\prime}\right) \\
& \text { s.t. } \\
x^{\prime}= & b^{\prime} P_{b}+g^{\prime}\left[1-P_{l}\right]-m^{\prime} P_{m}\left(\kappa^{\prime}\right) \\
a^{\prime}= & \left.b^{\prime}+\max \left\{0,\left(1-\delta^{\prime}\right) g^{\prime}-m^{\prime}\right)\right\}+(1-\tau) y^{\prime}
\end{aligned}
$$

This last problem can be conveniently expressed as a choice problem of just bond $b^{\prime}$ and leverage $\kappa^{\prime}=m^{\prime} / g^{\prime}$. Note that if $g^{\prime}=0$ the household cannot borrow and thus $\kappa^{\prime}=0$.First, we can write the last two equations in terms of $\kappa^{\prime}$ instead of $m^{\prime}$ :

$$
\begin{aligned}
& x^{\prime}=b^{\prime} P_{b}+g^{\prime}\left\{1-P_{l}-\kappa^{\prime} P_{m}\left(\kappa^{\prime}\right)\right\} \\
& \left.a^{\prime}=b^{\prime}+g^{\prime} \max \left\{0,\left(1-\delta^{\prime}\right)-\kappa^{\prime}\right)\right\}+(1-\tau) y^{\prime}
\end{aligned}
$$

Now we solve the first equation for $g^{\prime}$ to obtain

$$
\begin{aligned}
g^{\prime} & =\frac{x^{\prime}-b^{\prime} P_{b}}{1-P_{l}-\kappa^{\prime} P_{m}\left(\kappa^{\prime}\right)} \\
a^{\prime} & \left.=b^{\prime}+\frac{x^{\prime}-b^{\prime} P_{b}}{1-P_{l}-\kappa^{\prime} P_{m}\left(\kappa^{\prime}\right)} \max \left\{0,\left(1-\delta^{\prime}\right)-\kappa^{\prime}\right)\right\}+(1-\tau) y^{\prime}
\end{aligned}
$$

and thus the portfolio choice problem boils down to

$\left.w\left(x^{\prime}, y^{\prime}\right)=\max _{\substack{0 \leq b^{\prime} \leq x^{\prime} / P_{b} \\ 0 \leq \kappa^{\prime}}} \int_{\underline{\delta}}^{\infty} v\left\{b^{\prime}+\frac{x^{\prime}-b^{\prime} P_{b}}{1-P_{l}-\kappa^{\prime} P_{m}\left(\kappa^{\prime}\right)} \max \left\{0,\left(1-\delta^{\prime}\right)-\kappa^{\prime}\right)\right\}+(1-\tau) y^{\prime}, y^{\prime}\right\} d F\left(\delta^{\prime}\right)$

\subsubsection{Labor Income Process}

From the Tauchen procedure we obtain (after de-logging) the five labor productivity shock realizations $y \in\{0.3586,0.5626,0.8449,1.2689,1.9909\}$ and the following transition matrix:

$$
\pi=\left[\begin{array}{lllll}
0.7629 & 0.2249 & 0.0121 & 0.0001 & 0.0000 \\
0.2074 & 0.5566 & 0.2207 & 0.0152 & 0.0001 \\
0.0113 & 0.2221 & 0.5333 & 0.2221 & 0.0113 \\
0.0001 & 0.0152 & 0.2207 & 0.5566 & 0.2074 \\
0.0000 & 0.0001 & 0.0121 & 0.2249 & 0.7629
\end{array}\right]
$$


which in turn implies the stationary distribution $\Pi=(0.1907,0.2066,0.2053,0.2066,0.1907)$ and average labor productivity of one. 
8 Figures 
Figure 1: Housing Policy Function

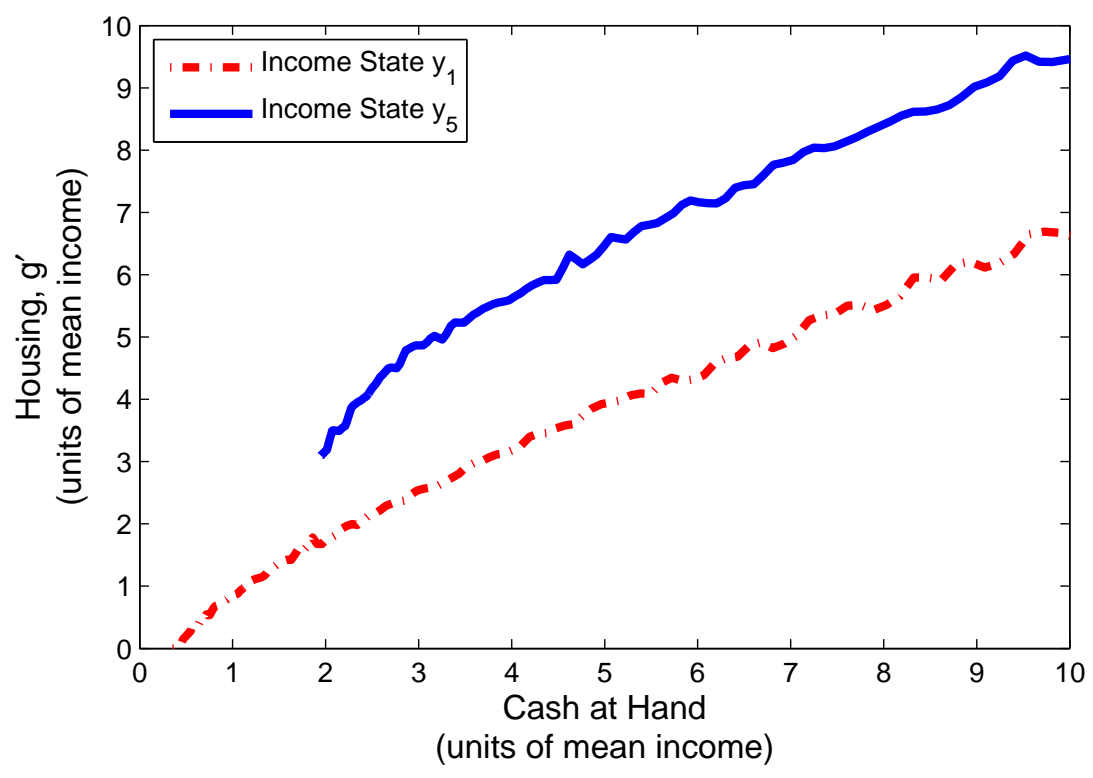


Figure 2: Leverage Policy Function

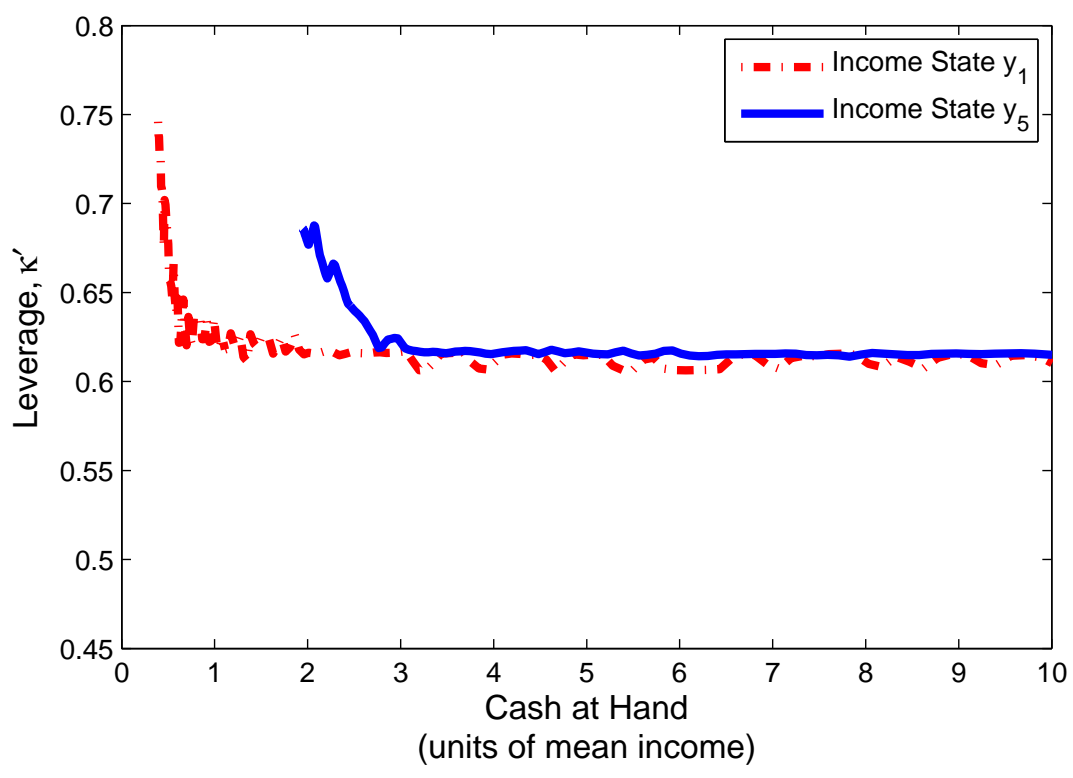


Figure 3: Bonds Policy Function

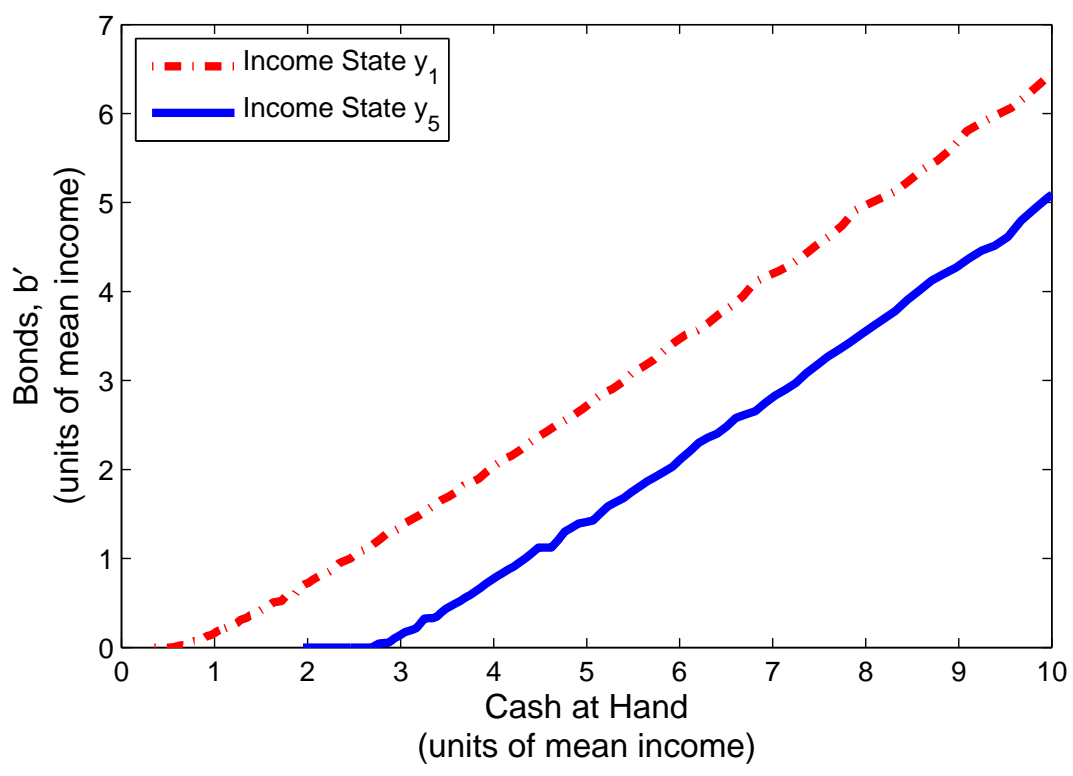


Figure 4: Housing Policy Function With and Without Subsidy
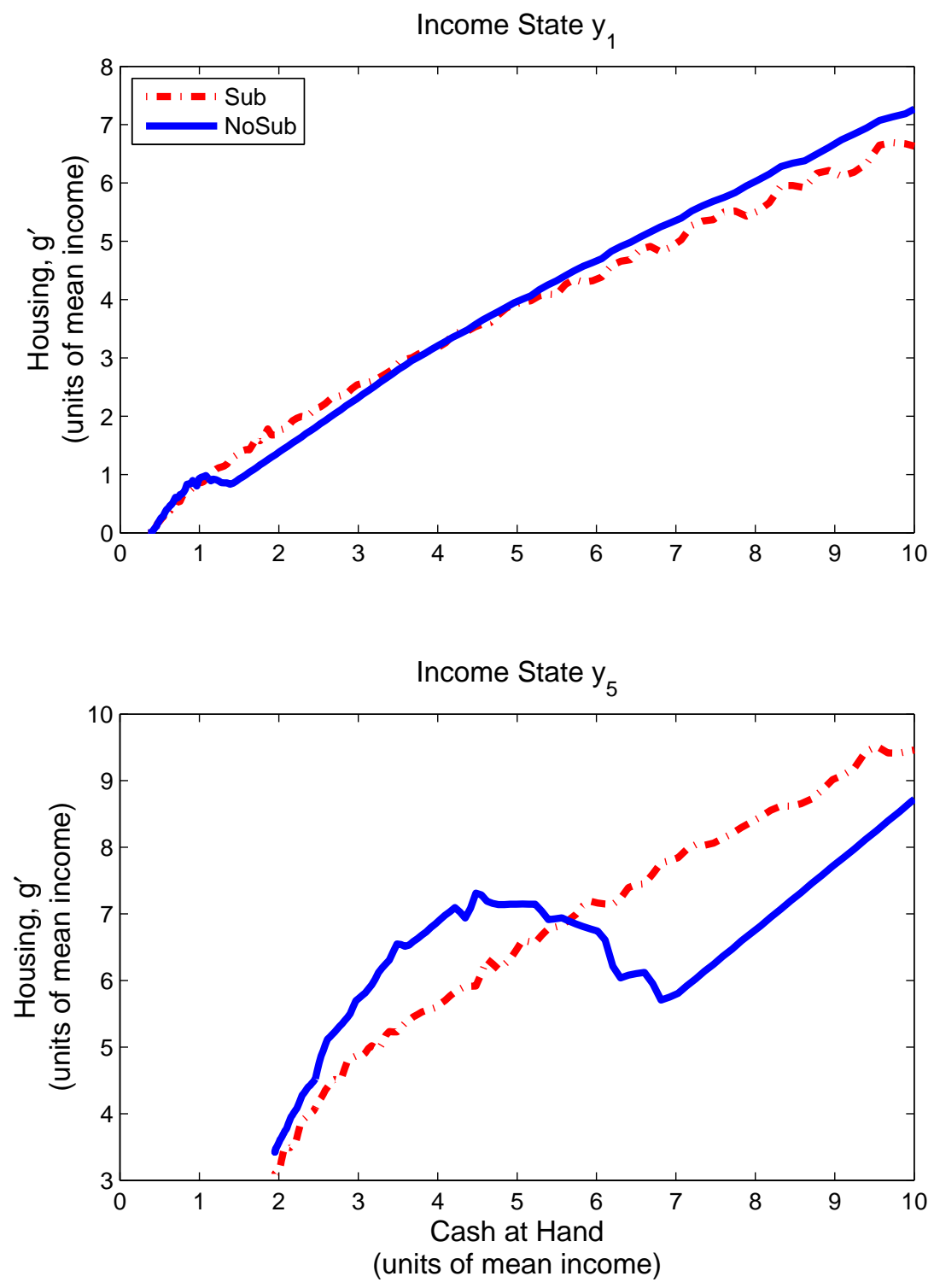
Figure 5: Leverage Policy Function With and Without Subsidy
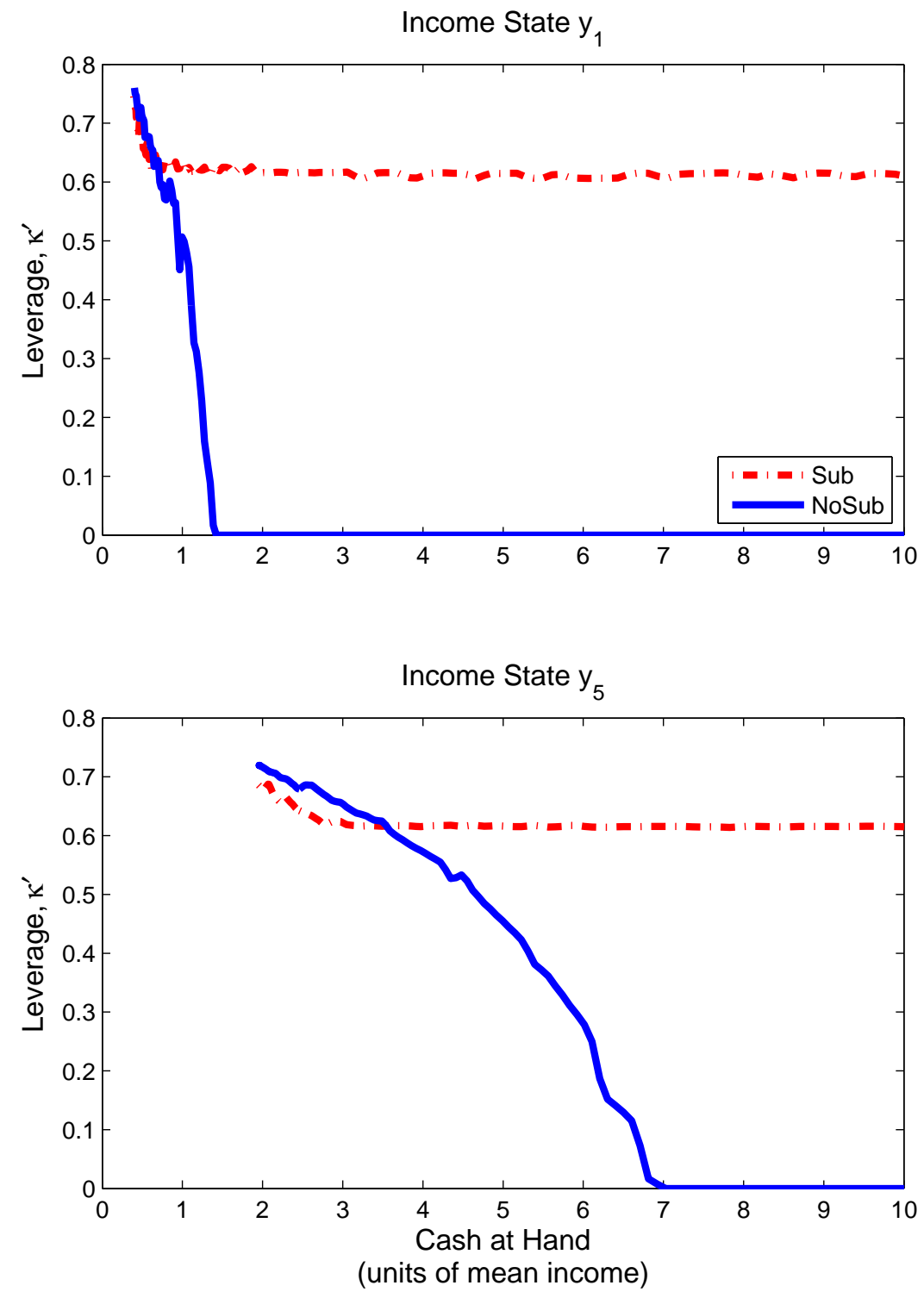
Figure 6: Bonds Policy Function With and Without Subsidy
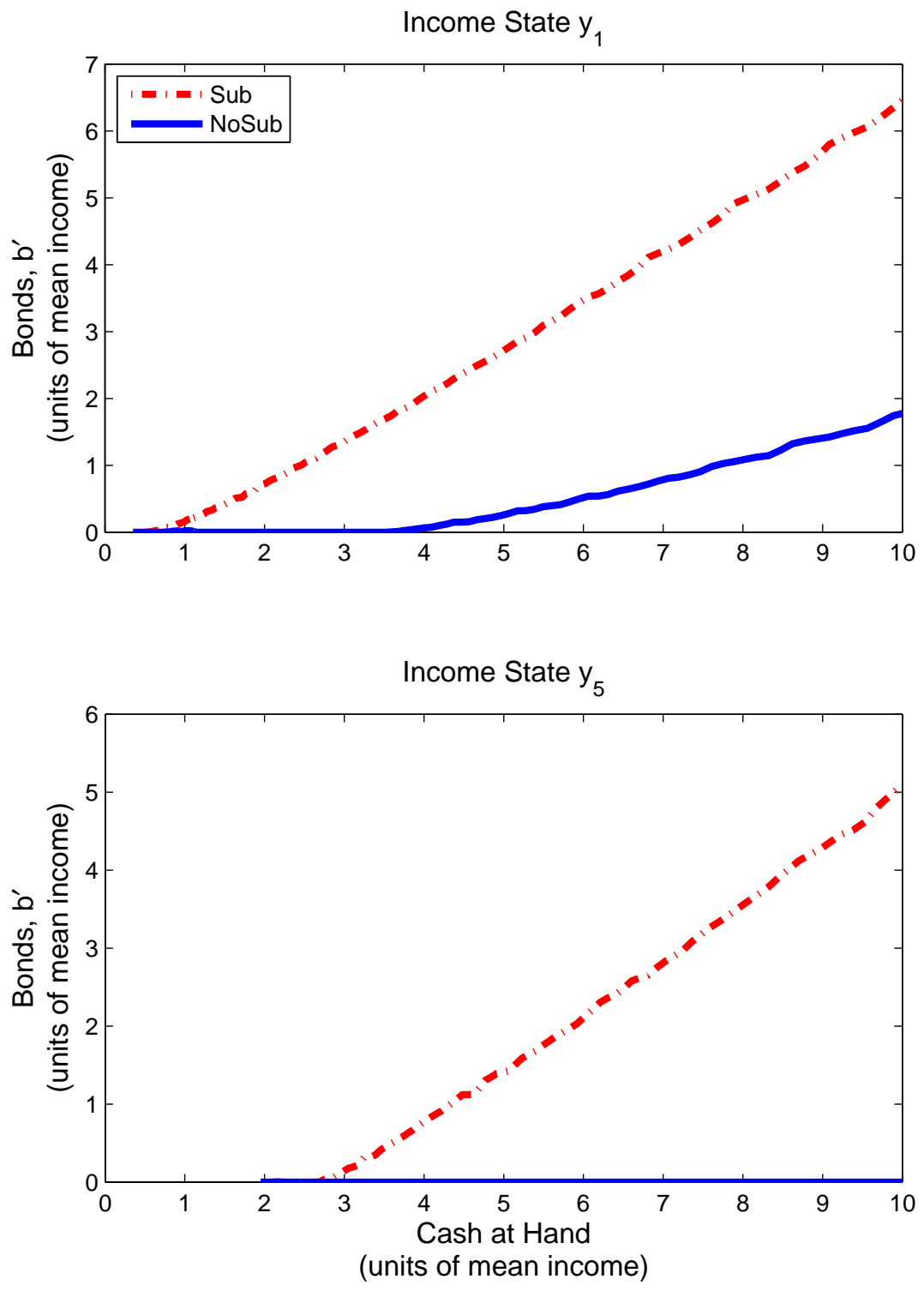
Figure 7: Home Equity Policy Function With and Without Subsidy
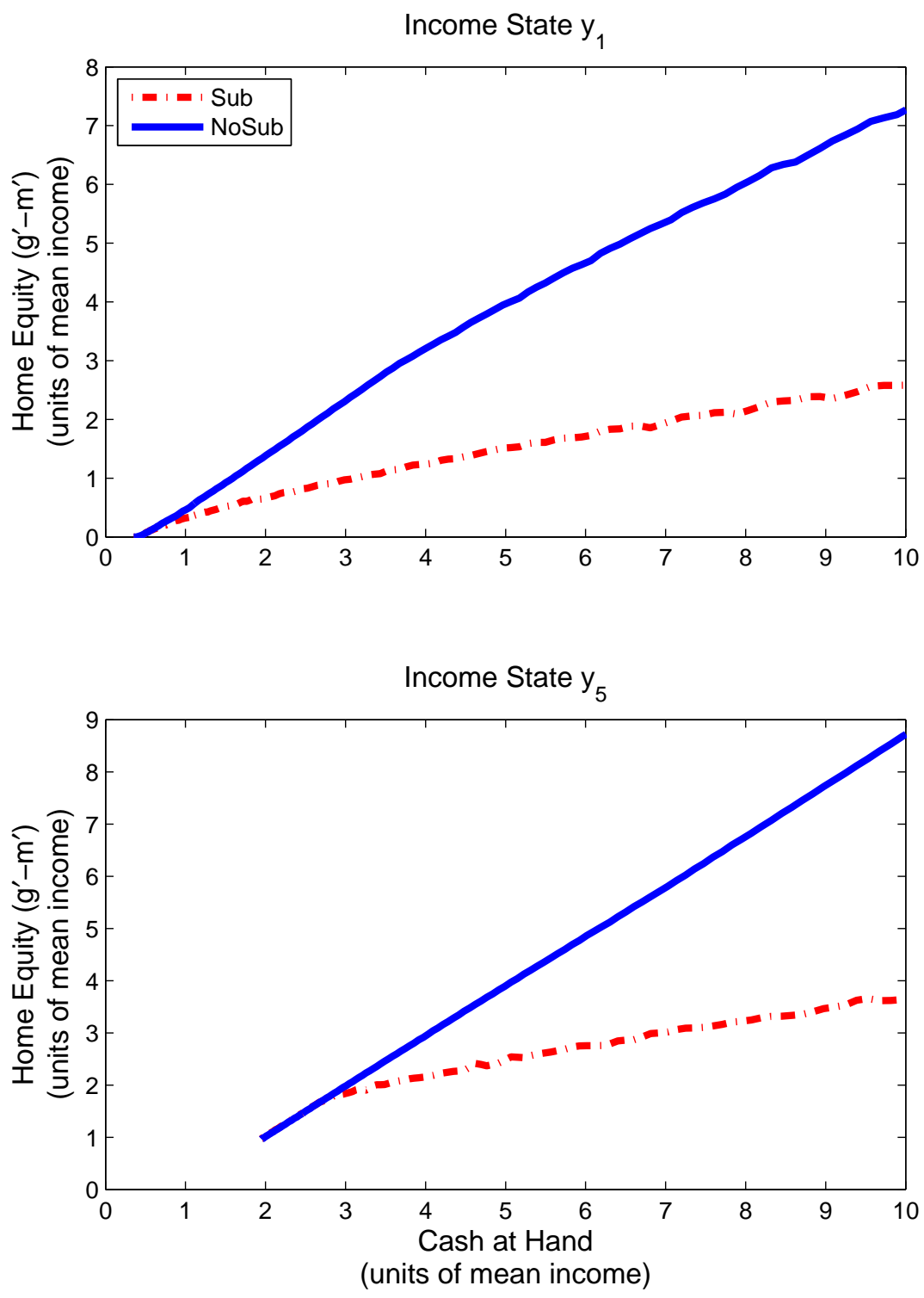
Figure 8: Distribution over Cash at Hand with and without Subsidy

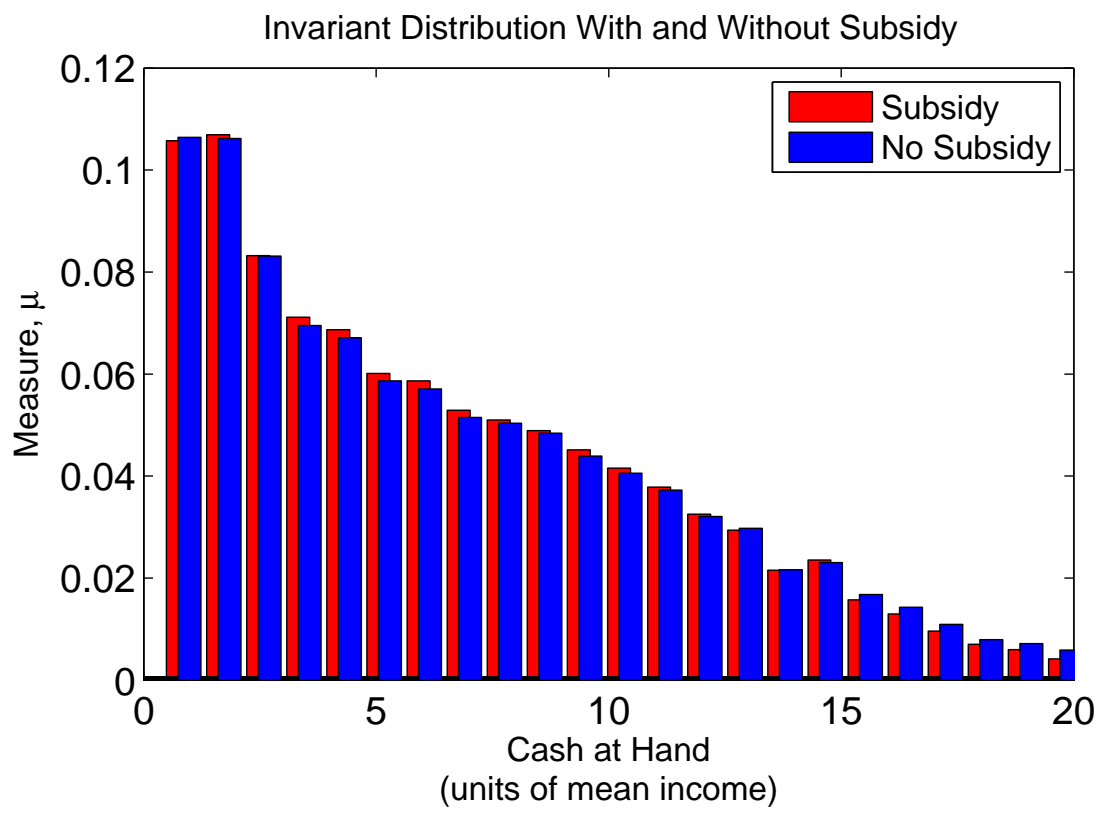


Figure 9: Welfare Comparison
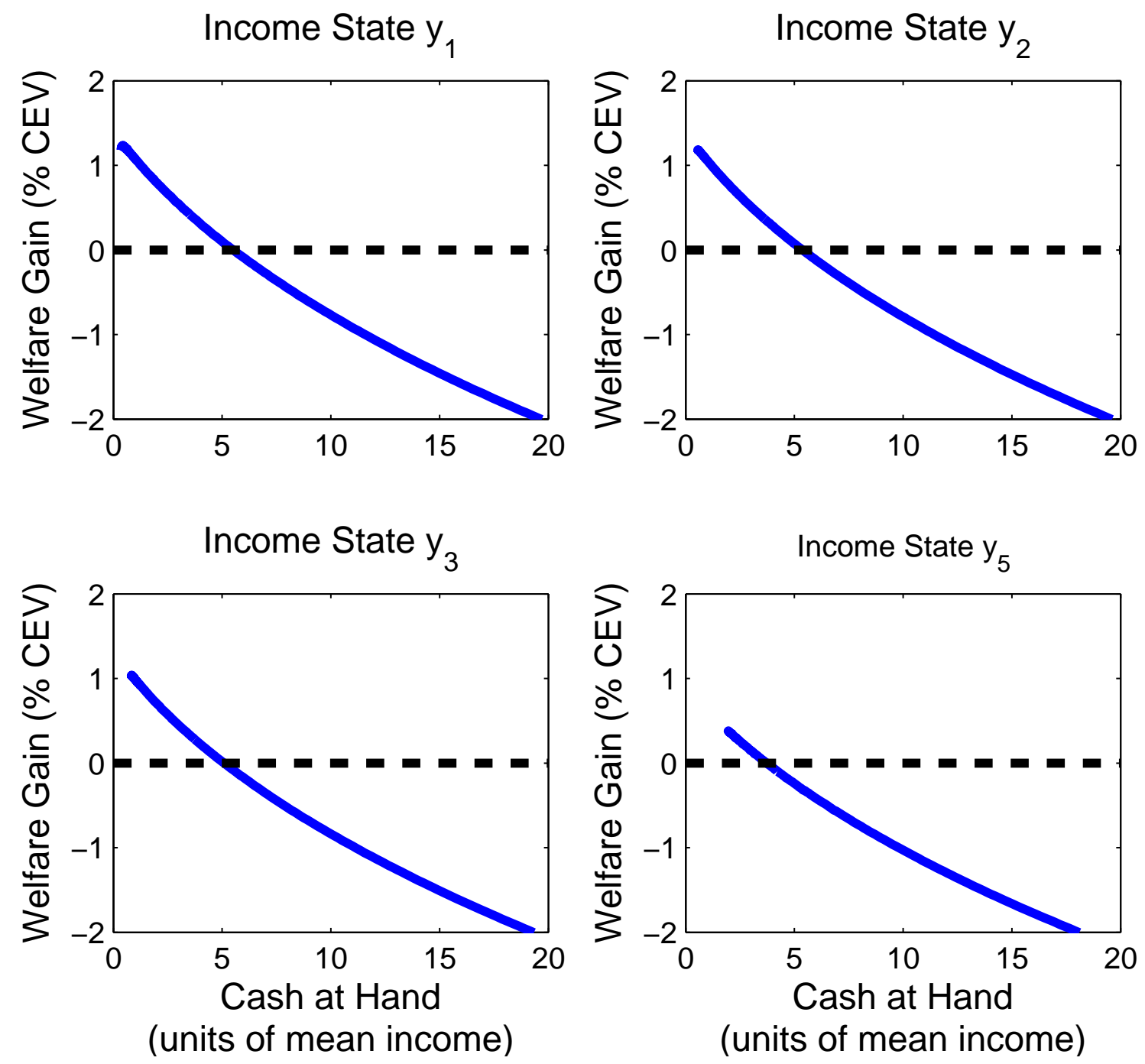